\title{
Globalization, rent protection institutions, and going alone in freeing trade
}

\author{
Wolf-Heimo Grieben ${ }^{\mathrm{a}, *}$, Fuat Şener ${ }^{\mathrm{b}}$ \\ a Department of Economics, University of Konstanz, 78457 Konstanz, Germany \\ ${ }^{\mathrm{b}}$ Department of Economics, Union College, Schenectady, NY 12308, USA
}

\section{A R T I C L E I N F O}

JEL classification:
F12
F43
$\mathrm{O} 31$
$\mathrm{O} 32$
$\mathrm{O} 34$
Keywords:
Globalization
Innovation
Imitation
Product cycle
Endogenous growth

\section{Introduction}

The past two decades have been marked by the entry of large developing countries, such as Argentina, Brazil, China, Egypt, India, Turkey, Poland and Romania into the world trading system. As shown in Fig. 1, between 1990 and 2002 the world trade share of middle-income countries has increased from 15 percent to 22 percent. During the 1983-2003 period, China as the world's most populous country has increased its share in global trade from 1.01 percent to 5.04 percent.

Moreover, during the eight GATT negotiation rounds from Geneva 1947-1948 to Uruguay 1986-1993, the average tariff rates among participants declined from $52.7 \%$ to $13.1 \%$ of the 1931 level, as shown in Table 1 . From earlier to later rounds, the number of participants increased significantly, mainly due to developing countries joining the GATT negotiations.

With more developing countries establishing international trade linkages and pursuing freer trade policies, these globalization trends are likely to continue in the following years.

Is 'globalization' good for economic growth? We analyze this question theoretically in a general-equilibrium North-South Schumpeterian growth model with a continuum of high-tech industries. ${ }^{1}$ Northern entrepreneurs participate

\footnotetext{
* Corresponding author. Tel.: +497531885192; fax: +497531884558.

E-mail addresses: heimo.grieben@uni-konstanz.de (W.-H. Grieben), senerm@union.edu (F. Șener).

${ }^{1}$ The empirical evidence on the trade-growth nexus is mixed: while the majority 'optimistic' view is that, mostly based on the Sachs-Warner criteria for openness, trade raises growth (see e.g. Lewer and Van den Berg, 2003; Wacziarg and Welch, 2008; Winters, 2004; Noguer and Siscart, 2005), other
} 


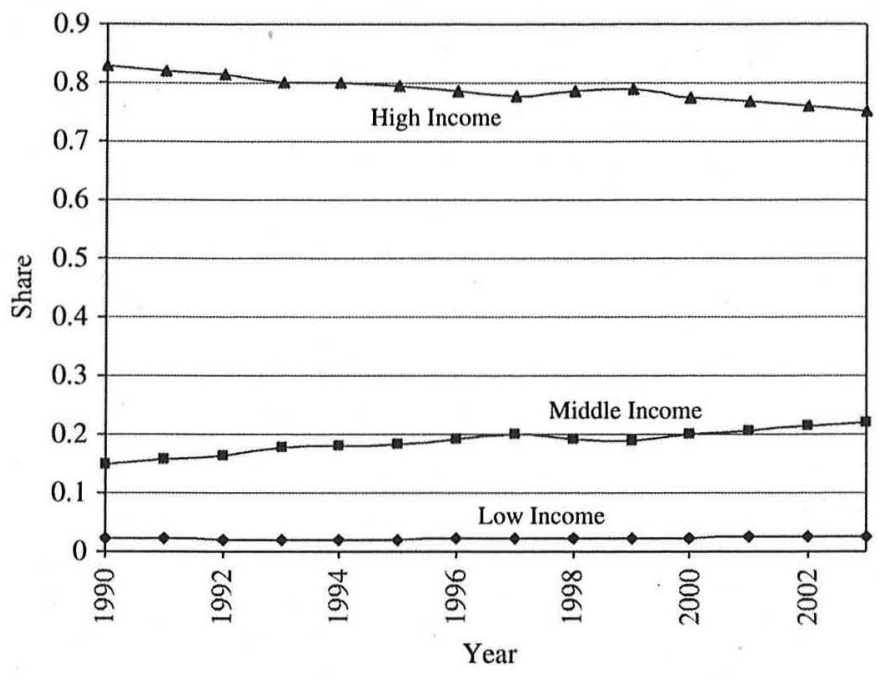

Fig. 1. World trade share of country groups. Data Source: World Bank (2005). For each country group, world trade share is imports plus exports of goods and services measured in current US dollars divided by the corresponding value for the world. Income divisions, which follow the World Bank classifications, are based on 2003 gross national income per capita levels: $\$ 765$ or less for low-income countries; $\$ 766-\$ 9385$ for middle-income countries (including China); $\$ 9386$ or more for high-income countries.

Table 1

Tariff reductions during GATT and WTO rounds.

\begin{tabular}{|c|c|c|c|}
\hline Round & Number of participants & Average $\%$ cut in all tariffs & Average tariff level as \% of 1931 level \\
\hline 948 & 23 & 21.9 & 52.7 \\
\hline & 13 & 1.9 & 51.7 \\
\hline & 38 & 3.0 & 50.1 \\
\hline Geneva II, 1956 & 26 & 3.5 & 48.9 \\
\hline Dillon, $1960-1962$ & 26 & 2.4 & 47.7 \\
\hline Kennedy, 1964-1967 & 62 & 36.0 & 30.5 \\
\hline Tokyo, 1973-1979 & 102 & 29.6 & 21.2 \\
\hline Uruguay, 1986-1993 & 123 & 38.0 & 13.1 \\
\hline Doha, 2001-? & $141^{a}$ & $?$ & ? \\
\hline
\end{tabular}

Sources: Van den Berg (2004), Table 8.1, p. 278; Neary (2004), Table 1, p. 321; www.wto.org.

a 141 at the start, 149 at Hong Kong Conference, December 2005.

in $R \& D$ races to innovate higher quality consumption goods. Southern entrepreneurs compete to imitate the current Northern production technologies. In each industry, the winner of the R\&D race establishes temporary monopoly power until driven out of the market by further innovation or imitation. Global economic growth is driven by the continuous arrival of higher quality goods through Northern R\&D races. During their tenure, Northern monopolists engage in RentProtection Activities (RPAs) to safeguard their monopoly profits. ${ }^{2}$ RPAs encompass all activities that deter the innovation and imitation efforts targeted at the incumbent firm (such as patent enforcement, practicing trade secrecy, and lobbying the government to promote stronger intellectual property rights protection). Northern innovation and Southern imitation rates are determined endogenously. With lower production costs in the South, successful imitation in a certain industry implies the shifting of production from the North to the South. This gives rise to North-South "product-cycle trade": the North exports newly invented goods that are not yet imitated, and the South exports imitated products. The governments in both the North and the South impose ad-valorem tariffs on high-tech imports.

\footnotetext{
(footnote continued)

researchers have important reservations on how the 'optimists' have derived and interpreted their results, and hence remain overall skeptic (see e.g. Rodríguez and Rodrik, 2000; Hallak and Levinsohn, 2008; Wälde and Wood, 2004). A recent thoughtful discussion of the potential of the Sachs-Warner criteria to measure the trade policy impact on growth is provided by Lucas (2009), who supports the 'optimistic' view.

${ }^{2}$ RPAs in an endogenous growth model are originally proposed by Dinopoulos and Syropoulos (2007). See Dinopoulos and Syropoulos (2007, pp. 310-312), Sener (2008, Footnote 20) and Scotchmer (2004, Chapter 7) and the references therein for detailed discussion and empirical evidence on RPAs in a closed economy setting. The available evidence suggests that patent enforcement by successful innovators is prevalent across all industries and costly to undertake. Many companies, especially small firms, cite this as a deterrent to their R\&D success. Lobbying activities to influence the judicial and legislative system are also well documented in the literature.
} 
We focus on two alternative aspects of globalization: increased trade integration of the South in the form of an expansion of the relative size of the South that is open to trade (modeled as an increase in the Southern population size relative to the $\operatorname{North}^{3}$ ), and incremental trade liberalization that takes the form of a reduction of ad-valorem import tariffs.

In our model, we make two distinctions which turn out to be crucial for our main findings on whether or not globalization raises growth. First, we differentiate between two institutional frameworks through which rent protection in the South may materialize. The evidence on RPAs in a North-South context suggests that such activities can take two broad forms. The first is through domestic legislative bodies and involves lobbying the government to influence traderelated legislations/treaties. ${ }^{4}$ We view this primarily as an activity that utilizes domestic resources (e.g., US firms hiring US lawyers to influence the US-China trade talks in an attempt to make the case for stronger IPR protection). The second is through the foreign judicial institutions and involves the standard patent enforcement mechanisms (patent litigation, administrative action, etc.). ${ }^{5}$ We view this primarily as an activity that utilizes foreign resources (e.g., US firms hiring Chinese lawyers for patent litigation in Chinese courts). We intend to capture this distinction in resource utilization by considering two cases:

1. Local-resource using rent protection: Southern resources are used for imitation-deterring activities and Northern resources are used for innovation-deterring activities;

2. Northern-resource using rent protection: Both activities are combined as general rent protection and use only Northern resources.

We find that in the Northern-resource-using case, increased trade integration of the South exerts a positive effect on imitation, innovation, and hence on economic growth. In the local-resource using case, imitation still increases, but the rates of innovation and economic growth can be lower (main result 1 ).

Second, we consider as our baseline setting a model in which only "high-tech" sector goods are produced in both countries. We then allow for a Southern "low-tech" sector that does not feature quality improvements and operates under free trade conditions. We find that without a low-tech sector, tariff changes have no impact on the rates of Northern innovation, Southern imitation, and economic growth (we refer to this as the "tariff-neutrality" result). If a low-tech sector exists (which we consider the more realistic case ${ }^{6}$ ), unilateral Northern trade liberalization for high-tech goods unambiguously increases Northern innovation, Southern imitation, and economic growth, whereas unilateral Southern trade liberalization has the exact opposite results. From a growth perspective, this provides the North with an argument for 'going alone' in freeing trade (main result 2).

Our model differs from the existing literature on endogenous growth and trade on five accounts. First, we consider economic integration and incremental trade liberalization in a North-South setting. The relevant product cycle literature mostly focuses on North-North settings with a few exceptions (e.g., Dinopoulos and Segerstrom 2007; Şener and Zhao 2009; Grieben 2005, 2009). Moreover, we introduce into our main North-South setting a Southern low-tech sector and show its crucial role in determining the impact of tariff reductions.

Second, we investigate the effects of unilateral trade liberalization by both the North and the South. Most of the existing literature studies bilateral trade liberalization. Our results show that Northern and Southern unilateral trade liberalization

\footnotetext{
${ }^{3}$ This exercise follows Lu (2007, p. 338) as well as Dinopoulos and Segerstrom (2007). The standard North-South product-cycle model essentially represents a world economy that consists of three regions: an Open North, an Open South, and a Closed South that has no contact with the open regions. Thus, an increase in the relative size of the Open South can appropriately capture the South's increased presence in the world trading system. This integration encapsulates two potential effects on Northern innovation incentives: on the one hand, more Southern labor resources allow the South to invest more in imitation, thereby increasing the imitation threat faced by Northern monopolists. On the other hand, more Southern consumers mean a larger market for sales of Northern incumbent firms, which raises monopoly profits.

${ }^{4}$ Lanjouw and Cockburn (2000) report on the significance of such US firms' lobbying activities. Scotchmer (2004, pp. 320-325) argues that the current US trade policy, in particular, the 1974 trade act and the subsequent amendments to its section 301 in 1984 and 1988 have provided an "automatic platform" for powerful lobbies (such as Intellectual Property Alliance, Business Software Alliance and International Federation of the Phonographic Industry) to influence the US government for promotion of increased global IPR protection. Scotchmer (2004, p. 323) also views the injection of IPRs into Generalized Agreement on Trade and Tariffs (GATT) negotiations in the 1990s as "perhaps the greatest victory of the copyright and patent lobby." Eventually, this led to the signing of the Trade Related Aspect of IPRs (TRIPS) under the World Trade Organization umbrella, which required the member countries to provide at least minimum standards of patent protection with regards to the length of the protection and the coverage of certain products.

${ }^{5}$ A significant number of IP-related cases that involve Northern innovators and Southern firms has been reported in specialized intellectual property journals, such as Managing Intellectual Property. Such cases have been prevalent in a wide range of industries (e.g., Pfizer against a dozen of Chinese pharmaceutical companies on the validity of Pfizer's patent covering Viagra ${ }^{\mathrm{TM}}$, settled by the Beijing High People's Court in October 2007 in favor of Pfizer; source: http://www.managingip.com/Article.aspx?ArticleID=1915362). It should be noted that international patenting by itself is a costly activity. For a single invention the total cradle to grave costs of patent coverage in 52 countries is estimated to be roughly $\$ 472,414$ (see Berrier, 1996 ). The costs range from a high of $\$ 40,000$ in Japan to a low of about $\$ 2000$ in South Africa with an average of $\$ 9085$. Sener (2006) and the references therein provide further details and examples on RPAs in a North-South context.

6 The existence of a low-tech sector only in the South implies that the unit cost of low-tech production in the North is prohibitively high for any Northern firm to successfully compete under free trade. Low-tech industries appear to be vanishing in high-wage countries, as already noted by Wood (1995, p. 65) when he criticizes factor-content studies for Northern developed countries: "[...] manufactured imports from developing countries [...] consist mostly of items of low skill intensity that are no longer produced on any significant scale in developed countries".
} 
have opposite effects on innovation and imitation. ${ }^{7}$ This issue cannot be addressed in a framework of symmetric iceberg trade costs like in Dinopoulos and Segerstrom (2007).

Third, we offer a scale-free endogenous growth model, which distinguishes our paper from the early literature (like Grossman and Helpman, 1991, or Rivera-Batiz and Romer, 1991) where the steady-state growth rate increases in the amount of resources allocated to R\&D. As a consequence of this scale effect, these models propose a positive relationship between economic integration and growth: in an integrated world economy, more workers can create more technical knowledge without duplicating each other's R\&D efforts, and R\&D returns are higher when technical knowledge can be applied to a larger market. Hence, economic growth should be higher than under autarky. However, despite clear evidence for increased global integration as stated above, and dramatically rising R\&D investments during the last decades (as documented e.g. in Jones, 1995a; Segerstrom, 1998), there has been no clear tendency for growth rates to increase in the advanced countries, which suggests that the scale effect is counterfactual. $^{8}$

Fourth, we incorporate RPAs by incumbents into our North-South model. We find that the effects of economic integration crucially depend on the location of these activities. The only other North-South model with rent-protection activities is the companion paper by Sener (2006) ${ }^{9}$ Relative to other two-country Schumpeterian non-scale growth models like Dinopoulos and Segerstrom (1999a, 2007), the benefit of having RPAs is twofold: it provides microeconomic foundations for explaining increasing R\&D difficulty, and enables us to study globalization effects under different institutional set ups for RPAs.

Fifth, our model features fully endogenous growth, that is, the steady-state growth rate is a function of the fraction of resources allocated to R\&D and thus affected by a wide range of parameters. Tariff rates and the degree of international integration can have an impact on the long-run growth rate by altering this fraction. Within the non-scale growth literature, this result differentiates our paper from the semi-endogenous growth models such as Dinopoulos and Segerstrom (2007), where the steady-state growth rate is pinned down by exogenous parameters and unaffected by tariffs and increased integration. ${ }^{10}$

The remainder of this paper is organized as follows. Section 2 presents the elements of the baseline model in which RPAs exclusively use Northern resources and there is no low-tech sector in the South. Section 3 analyses the steady-state effects of increased Southern trade integration and unilateral trade liberalization. Section 4 provides the two crucial extensions of the baseline model (Southern-resource-using imitation-deterring activities, Southern low-tech sector), which are shown to change the main results. Section 5 concludes. Formal derivations and proofs are relegated to several appendices.

\section{The model}

\subsection{Household behavior}

The world economy consists of two countries, the North and the South, indexed by $i \in\{N, S\}$, respectively (variables and parameters without country index are common to both countries). Each country has a fixed number of identical households, and the number of household members $N_{t i}$ at time $t$ within each country $i$ is identical at each point in time. For simplicity, we assume that the number of households (but not of household members) is normalized to one in each country. We allow for different initial numbers of household members for both countries, $N_{0 N} \neq N_{0 s}$, but these are growing at the common rate $n>0$, thus the population size and also the labor force in country $i$ at time $t, N_{i}(t)$, equal $N_{0 i} e^{n t}$. The representative household maximizes the utility function

$$
U_{i}(t)=\int_{0}^{\infty} e^{-\rho t} \log u_{i}(t) d t \text { for } i=N, S,
$$

\footnotetext{
${ }^{7}$ To the best of our knowledge, this is a new finding in the literature. Dinopoulos and Syropoulos (1997), Baldwin and Forslid (1999), and Ben-David and Loewy (2000) also study unilateral trade liberalization but consider settings with structurally identical countries that do not differentiate between the Northern and Southern research activities as innovation and imitation targeted.

${ }^{8}$ Among the many non-scale growth models that have emerged since the "Jones critique", we note Jones (1995b), Young (1998), Peretto (1998), Segerstrom (1998), Peretto and Smulders (2002), Dinopoulos and Segerstrom (1999a), and Şener (2001), where only the latter two consider international trade (in a symmetric North-North setting) at the same time. For further insightful discussion on growth with and without scale effects, see e.g. Dinopoulos and Thompson (1999), Jones (1999, 2005), Christiaans (2004), and Laincz and Peretto (2006).

9 That paper differs from the current paper in a number of ways. Şener (2006) considers a free trade model, which studies the effects of strengthening Southern IPRs, instead of economic integration and tariff effects. In addition, Sener considers only the local-resource using RPA case and does not model a Southern low-tech sector. However, to investigate the impact of IPRs from a broad perspective, Șener (2006) allows for North-South foreign direct investment (FDI) and endogenous fragmentation of production within multinationals, which are beyond the scope of this paper. The effects of multinational firms in scale-free endogenous growth models with North-South trade have also been addressed by Dinopoulos and Segerstrom (2009), and Gustafsson and Segerstrom (2008).

${ }^{10}$ Madsen $(2007,2008)$ empirically rejects the assumption of decreasing returns to R\&D, which removes the scale effect in semi-endogenous growth models, and he finds supporting evidence for Schumpeterian models of non-scale growth, which uphold the assumption of constant returns to R\&D. Ha and Howitt (2007) also argue that the predictions of the fully endogenous growth models are more consistent with time series data from advanced countries than those of semi-endogenous growth models. Important fully endogenous growth models include Howitt (1999), Segerstrom (2000), Dalgaard and Kreiner (2001), and Strulik (2005), but they all are confined to a closed economy and stress the role of public policies to affect the long-run growth rate. However, based on more general considerations, Temple (2003, pp. 501-502) points out that emphasizing the different long-run policy implications of semi- and fully-endogenous growth models may be of little practical relevance.
} 
where $\rho>n$ is the subjective discount (or time preference) rate, and where the instantaneous logarithmic utility function of each household member is

$$
\log u_{i}(t) \equiv \int_{0}^{1} \log \left[\sum_{j} \lambda^{j(\omega, t)} x_{i}(j, \omega, t)\right] d \omega \quad \text { for } i=N, S .
$$

$\lambda>1$ is the size of each quality improvement, $j(\omega, t)$ is the number of successful innovations in industry $\omega \in[0,1]$ up to time $t$, and $x_{i}(j, \omega, t)$ is the per-capita demand for a product with $j$ quality improvements in industry $\omega$ at time $t$. Hence, as is standard in quality-ladder models, product quality starts at $\lambda^{0}=1$ in any industry $\omega$ and improves at discrete steps with each successful innovation, which is governed by a stochastic process.

The household optimization process consists of two steps. The first step is to allocate consumption expenditure across products to maximize $u_{i}(t)$ with given product prices. Since products in a typical industry $\omega$ differ only in their quality, and $\lambda$ units of quality $j$ are a perfect substitute for one unit of quality $j+1$, households purchase in each industry only the product with the lowest quality-adjusted price. In addition, since products enter (2) symmetrically, each household spreads consumption expenditure evenly across product lines. This results in a unit-elastic per-capita demand function $x_{i}(\omega, t)=c_{i}(t) / p(\omega, t)$ in each industry $\omega$, where $c_{i}(t)$ is the consumption expenditure per capita in country $i$ at time $t$, and $p(\omega, t)$ is the market price for the purchased product. ${ }^{11}$

Given the static demand functions, the second step is to determine the consumption expenditure path over time. This involves maximizing

$$
\int_{0}^{\infty} e^{-\rho t} \log c_{i}(t) d t \text { for } i=N, S,
$$

subject to the intertemporal budget constraint

$$
\dot{B}_{i}(t)=W_{i}(t)+r(t) B_{i}(t)-c_{i}(t),
$$

where $B_{i}(t)$ denotes the per-capita stock of financial assets owned by the household (that arises from the ownership of firms earning monopoly profits to be discussed later), $W_{i}(t)$ is the per-capita wage income earned by the household perperiod, and $r(t)$ is the instantaneous rate of return in the global market. The solution to this dynamic optimization problem is the familiar Euler equation ("Keynes-Ramsey rule")

$$
\dot{c}_{i}(t) / c_{i}(t)=r(t)-\rho \text { for } i=N, S .
$$

At the steady-state equilibrium, $c_{i}$ will be constant since the wage rate and labor supply per worker will be constant, thus $r(t)=\rho$. Since we focus on steady-states and consider structurally identical industries, we henceforth drop the time index $t$ and the industry index $\omega$ where appropriate.

\subsection{Labor and activities}

Labor is the only factor of production and is immobile across countries. In the North, the labor force consists of generalpurpose and specialized workers, with the proportion of the former given as $1-s_{N}$ and that of the latter given as $s_{N} \in(0,1)$. In the North, there are three types of activities: innovation, manufacturing of final goods and rent-protection. Generalpurpose workers can be employed in manufacturing or innovation, whereas specialized workers (like lawyers or lobbyists) are only employed in RPAs. ${ }^{12}$ In the South, there is only general-purpose labor, which can be employed in manufacturing of final goods or imitation, which are the only types of activities. In an extension of the baseline model, Section 4.1 introduces Southern specialized labor, which is employed in RPAs.

\subsection{Industry structure and product markets}

The world economy consists of a continuum of structurally identical industries indexed by $\omega \in[0,1]$, i.e. the mass of industries is normalized to unity. In the North, entrepreneurs participate in innovation races to discover the technology of producing next-generation consumer goods, where each innovation improves the existing generation by a quality step of size $\lambda>1$. In the South, entrepreneurs participate in imitation races to acquire the technology of producing currentgeneration products, which refer to the existing state-of-the-art products manufactured by the current Northern quality leader in industry $\omega$. Producer firms compete to offer the lowest quality-adjusted price given their state of technology and regional factor prices. Northern entrepreneurs target their innovation efforts at all industries, while Southern entrepreneurs target their imitation efforts only at industries with a Northern quality leader since price competition

\footnotetext{
11 In an extension of the basic model, in Section 4.2 we will introduce a "low-tech sector" where goods of constant quality are produced. Then, we will term the goods we have been discussing so far as "high-tech goods".

12 This labor assignment follows Dinopoulos and Syropoulos (2007). We note that this is indeed a restrictive assumption; however; its advantage is that it yields fully endogenous growth with a parsimonious structure by creating a link between the innovation rate and the Northern relative wage rate between specialized and general-purpose labor. We will later discuss the robustness of our main results with respect to alternative labor assignments.
} 
among two Southern firms with identical technologies for the same industry $\omega$ would imply zero profits. As is usual in neo-Schumpeterian growth theory, whenever a higher quality product is discovered in the North, the technology of producing the previous-generation product becomes common knowledge in the world economy.

In both countries, production of one unit of final goods requires one unit of general-purpose labor, regardless of the quality level of the manufactured goods. Let $w_{L N}$ represent the wage rate of general-purpose labor in the North, while the Southern wage rate is normalized to 1 . For each industry, there are two possible structures at any point in time. Whenever a Northern entrepreneur discovers a next-generation product, the resulting structure is a Northern industry, in which the Northern quality leader competes with Southern followers that have access to the one-step down technology. Whenever a Southern entrepreneur acquires the technology of producing a current-generation product, the resulting structure is a Southern industry, in which a successful Southern imitator competes with a Northern incumbent, where both firms have access to the same state-of-the-art technology. Northern (Southern) firms face an ad-valorem import tariff rate of $\tau_{S}\left(\tau_{N}\right)$ in the Southern (Northern) market. According to the terminology of Dinopoulos and Segerstrom (1999b, p. 194), these are "rent-extracting", but not "protective" tariffs: they transfer rents from foreign quality leaders to domestic governments in both countries, but are not large enough to enable domestic follower firms to survive competition from foreign quality leaders.

Consider first the profits of the Northern quality leader who competes with Southern followers in both Northern and Southern markets. ${ }^{13}$ In the Northern market, Southern followers can produce the one-step-down quality product at the marginal cost of 1 . Under marginal cost pricing and with tariffs in place, the Southern followers can offer their goods to the Northern consumers at a price $1+\tau_{N}$. In this case, the Northern quality leader charges the limit price $p_{N}^{N}=\lambda\left(1+\tau_{N}\right)$ and drives the Southern followers out of the market. The profits of the Northern quality leader from sales in the Northern market are:

$$
\pi_{N}^{N}=\frac{c_{N} N_{N}}{\lambda\left(1+\tau_{N}\right)}\left[\lambda\left(1+\tau_{N}\right)-w_{L N}\right]=c_{N} N_{N}\left[1-\frac{w_{L N}}{\lambda\left(1+\tau_{N}\right)}\right]
$$

Intuitively, the existence of tariffs enables the local producer to raise its price and thus enjoy higher profits from local sales.

In the Southern market, Southern followers under marginal cost pricing can offer a price of 1 . The Northern quality leader faces an ad-valorem tariff rate of $\tau_{S}$. To capture the Southern market, the Northern firm must set its price such that the price faced by the Southern consumers does not exceed $\lambda$. This implies that the Northern firm's limit price is $p_{N}^{S}=\lambda$, of which the firm receives $\lambda /\left(1+\tau_{S}\right)$ per unit sold. The profits of the Northern quality leader from sales in the Southern market are:

$$
\pi_{N}^{S}=\frac{c_{S} N_{S}}{\lambda}\left(\frac{\lambda}{1+\tau_{S}}-w_{L N}\right)
$$

For $\pi_{N}^{S}>0$, we need $\tau_{S}<\left(\lambda / w_{L N}\right)-1$. Total profits from sales of Northern monopolists are:

$$
\pi_{N}^{P}=\pi_{N}^{N}+\pi_{N}^{S}=c_{N} N_{N}\left[1-\frac{w_{L N}}{\lambda\left(1+\tau_{N}\right)}\right]+c_{S} N_{S}\left(\frac{1}{1+\tau_{S}}-\frac{w_{L N}}{\lambda}\right)
$$

Consider next the profits of the successful Southern imitator who competes with the Northern quality leader in both Northern and Southern markets. ${ }^{14}$ In the Southern market, under marginal cost pricing and with tariffs in place, the Northern firm can offer its product to Southern consumers at a price of $w_{L N}\left(1+\tau_{S}\right)$. In this case, the Southern imitator charges the limit price $p_{S}^{S}=w_{L N}\left(1+\tau_{S}\right)$ and drives the Northern firm out of the market. The profits of the Southern imitator from sales in the Southern market are:

$$
\pi_{S}^{S}=\frac{c_{S} N_{S}}{w_{L N}\left(1+\tau_{S}\right)}\left[\left(1+\tau_{S}\right) w_{L N}-1\right]=c_{S} N_{S}\left[1-\frac{1}{w_{L N}\left(1+\tau_{S}\right)}\right] .
$$

In the Northern market, the Northern firm, under marginal cost pricing, can offer a price of $w_{L N}$. The Southern imitator faces an ad-valorem tariff rate of $\tau_{N}$. To capture the Northern market, the Southern imitator must set its price such that the price faced by the Northern consumers does not exceed $w_{L N}$. This implies that its limit price is $p_{S}^{N}=w_{L N}$, of which the firm receives $w_{L N} /\left(1+\tau_{N}\right)$ per unit sold. The profits of the Southern imitator from sales in the North are:

$$
\pi_{S}^{N}=\frac{c_{N} N_{N}}{w_{L N}}\left(\frac{w_{L N}}{1+\tau_{N}}-1\right)
$$

\footnotetext{
${ }^{13}$ Northern followers' unit cost is $w_{L N}$ whereas the Southern followers' unit cost is 1 . Northern followers cannot compete with Southern followers in the Southern market if $w_{L N}\left(1+\tau_{N}\right)>1$. This condition holds automatically given that $w_{L N}>1$ at the steady state. Moreover, Northern followers cannot compete with Southern followers in the Northern market provided $w_{L N}>1+\tau_{N}$. We assume that this restriction holds which implies that Southern imitators realize positive profits from sales in the North as is shown further below.

${ }^{14}$ The followers in both regions are undercut by the top-quality producers and exit the market.
} 
For $\pi_{S}^{N}>0$, we need $\tau_{N}<w_{L N}-1$. Total profits from sales of Southern monopolists are:

$$
\pi_{S}=\pi_{S}^{S}+\pi_{S}^{N}=c_{S} N_{S}\left[1-\frac{1}{w_{L N}\left(1+\tau_{S}\right)}\right]+c_{N} N_{N}\left(\frac{1}{1+\tau_{N}}-\frac{1}{w_{L N}}\right)
$$

Finally note that in equilibrium, positive rates of innovation and imitation require positive profits of both successful Northern innovators and Southern imitators, thus $1+\tau_{N}<w_{L N}<\lambda /\left(1+\tau_{S}\right)$ must be fulfilled: the lower bound for the Northern general-purpose wage rate ensures both $\pi_{S}^{S}>0$ and $\pi_{S}^{N}>0$, while the upper bound for $w_{L N}$ ensures both $\pi_{N}^{N}>0$ and $\pi_{N}^{S}>0$.

While Northern quality leaders earn monopoly profits, they face the threat of innovation from the North and imitation from the South. To safeguard their monopoly positions, the incumbents undertake RPAs. These can take the form of patent enforcement, practicing trade secrecy, lobbying the government to promote stronger intellectual property rights protection, corruption to influence the legal and political system, and such. RPAs work to deter the innovation and imitation efforts targeted at the incumbent. To conduct RPAs, each Northern incumbent hires Northern specialized labor at a wage rate of $w_{H N}$. The cost of performing $X$ units of RPAs is $w_{H N} \gamma X$, where $\gamma$ is the unit labor requirement of such activities. Hence, a Northern incumbent's profit flow net of RPA costs equals:

$$
\pi_{N}=\pi_{N}^{P}-w_{H N} \gamma X
$$

\subsection{Technology of innovation and imitation}

In the North, there are sequential and stochastic R\&D races in each industry $\omega \in[0,1]$ to discover the next-generation product on the industry-specific quality ladder. The R\&D technology is identical across Northern firms: by using generalpurpose labor, the instantaneous probability of innovation success (Poisson arrival rate) $l_{j}$ by firm $j$ is given as

$$
l_{j}=R_{j} / D \text { with } \dot{D}=n_{N} \delta X,
$$

where $R_{j}$ represents the intensity of innovation activities undertaken by a typical Northern entrepreneur $j$ targeting industry $\omega$, and $D$ measures the difficulty of targeting innovation at industry $\omega$. According to (8), $D$ is modeled as a stock variable, ${ }^{15}$ where $n_{N}$ is the proportion of industries located in the North, $X$ is the flow of RPAs undertaken by the Northern incumbent in industry $\omega$, and $\delta$ measures the effectiveness of these RPAs. Hence, whenever an industry is registered as a Northern industry - the probability of which is equal to $n_{N}$ in equilibrium - the Northern incumbents undertake RPAs, which increases the stock of R\&D difficulty in that industry by $\delta X$. Since the $l_{j}$ are independently distributed across firms and industries, the Poisson arrival rate for innovation at the industry level (which is 'the' Northern innovation rate) equals

$$
\imath=\sum_{j} l_{j}=R / D \text { with } R=\sum_{j} R_{j} .
$$

A constant steady-state innovation rate requires that R\&D difficulty $D$ must grow at the same rate as resources devoted to R\&D, which in equilibrium grows at the rate of population growth $n$. Hence, $\dot{D} / D=n$ is required. Using this and (8), we obtain the following expression for the stock of R\&D difficulty along any steady-state growth path: ${ }^{16}$

$$
D=n_{N} \delta X / n \text {. }
$$

Analogously, the instantaneous probability of imitation success (Poisson arrival rate) $\mu_{j}$ by any Southern firm $j$ is given as

$$
\mu_{j}=M_{j} / D
$$

with $\dot{D}$ as in (8), and $D$ now measures the difficulty of targeting imitation at industry $\omega$ as in (10). Note that RPAs are modeled as a general activity that deters both innovation and imitation simultaneously; hence, $D$ stands for both innovation and imitation difficulty (in Section 4.1 we differentiate between innovation- and imitation-deterring activities and their resource requirements). Therefore, the Poisson arrival rate for imitation at the industry level equals

$$
\mu=\sum_{j} \mu_{j}=M / D \text { with } M=\sum_{j} M_{j} .
$$

Since Southern entrepreneurs target only Northern industries, the economy-wide Southern imitation rate is given as $m \equiv \mu n_{N}$. Northern incumbent firms are driven from the market at the replacement rate $\imath^{+} \mu$.

\footnotetext{
${ }^{15}$ Modeling R\&D difficulty $D$ as a stock variable better captures the persistence of the institutional and legal framework surrounding intellectual property rights protection than the alternative modeling as a flow variable in Dinopoulos and Syropoulos (2007). All results are robust to assuming a constant depreciation rate for R\&D difficulty.

${ }^{16}$ The introduction of R\&D difficulty via RPAs removes the scale effects from the model. An alternative would be the "permanent effects on growth" (PEG) specification, as suggested by Dinopoulos and Segerstrom (1999a), which we analyze in Appendix R.1 (available from the authors upon request). The main results are robust to this alternative specification.
} 


\subsection{Optimal innovation and imitation decisions}

In the North, general-purpose labor is hired for performing innovative R\&D. The cost of conducting $R_{j}$ units of innovative activity is $w_{L N} a_{t} R_{j}$, where $a_{l}$ is the unit labor requirement of innovation. Imposing the usual free-entry assumption for R\&D races, expected profits from $R \& D$ are competed away, and the maximization problem yields

$$
\max _{R_{j}} \frac{v_{N} R_{j}}{D} d t-w_{L N} a_{i} R_{j} d t \Rightarrow v_{N}=w_{L N} a_{l} D
$$

where $v_{N}$ is the valuation of a successful Northern innovator. In the South, general-purpose labor is hired for performing imitative $R \& D$. The cost of conducting $M_{j}$ units of imitative activity in the South is $a_{\mu} M_{j}$ (given that the Southern wage rate is normalized to 1), where $a_{\mu}$ is the unit labor requirement of imitation. Under free entry into imitation, expected profits from $\mathrm{R} \& \mathrm{D}$ are competed away again, and the maximization problem yields

$$
\max _{M_{j}} \frac{v_{S} M_{j}}{D} d t-a_{\mu} M_{j} d t \Rightarrow v_{S}=a_{\mu} D,
$$

where $v_{S}$ is the valuation of a successful Southern imitator.

\subsection{Stock markets}

As usual in Schumpeterian growth models, household savings are channeled to firms investing in R\&D by means of a global stock market. Over any time period $d t$, the stockholders of a successful Northern innovating firm receive dividend payments $\pi_{N} d t$. With probability $(l+\mu) d t$, the firm is driven out of the market and the stockholders face a capital loss of size $v_{N}$. With probability $1-(l+\mu) d t$, the firm maintains its monopoly position and the stockholders experience a capital gain or loss given by $\dot{v}_{N} d t$. Households can engage in complete diversification of their asset portfolio to eliminate the industryspecific risk of unsuccessful R\&D expenditure, hence in an arbitrage-free asset market equilibrium, the expected return from a stock issued by a successful innovator $\pi_{N} d t-v_{N}(l+\mu) d t+\dot{v}_{N} d t(1-(l+\mu) d t)$ must equal the return of a risk-free asset that pays the market interest rate on an investment of equal size during the same time period, $r v_{N} d t$. Imposing this condition for $d t \rightarrow 0$ yields

$$
v_{N}=\frac{\dot{\pi}_{N}}{r+\imath+\mu-\left(\dot{v}_{N} / v_{N}\right)} \text {. }
$$

Similarly, the no-arbitrage condition for investments in Southern R\&D firms (which do not face the risk of imitation) yields

$$
v_{S}=\frac{\pi_{S}}{r+l-\left(\dot{v}_{S} / \nu_{S}\right)} .
$$

\subsection{Optimal rent protection activities by Northern incumbents}

Substituting $D$ from (10) into (9) and (12), we derive $\iota(X)=\left(R n / n_{N} \delta X\right)$ and $\mu(X)=\left(M n / n_{N} \delta X\right)$, which clearly show that a higher level of RPAs $X$ reduces both $l$ and $\mu$ and thus diminishes the threat of replacement faced by the incumbent. The incumbent avoids the capital loss $v_{N}$ and realizes the change in its valuation $\dot{v}_{N}$ by the extent of the decline in $l$ and $\mu$ per unit of time. In the meanwhile each unit of RPA costs $w_{H N} \gamma$ per unit of time. When choosing the optimal level of $X$, Northern incumbents weigh the gains against the costs at the margin. Formally, they choose $X$ to maximize the expected returns on their stocks

$$
\left(\pi_{N}^{P}-w_{H N} \gamma X\right) d t-v_{N}[\imath(X)+\mu(X)] d t+\dot{v}_{N} d t\{1-[\imath(X)+\mu(X)] d t\},
$$

where (7) is used for $\pi_{N}$ and the expressions for $\imath(X)$ and $\mu(X)$ are from above. Setting the derivative of the above expression with respect to $X$ to zero, using $d \imath(X) / d X=-\imath / X<0$ and $d \mu(X) / d X=-\mu / X<0$, and taking limits as $d t \rightarrow 0$, we derive the firstorder condition for the optimal $X$ as:

$$
X=v_{N}(l+\mu) /\left(w_{H N} \gamma\right)
$$

Intuitively, the optimal level of RPAs $X$ increases with the firm value $v_{N}$ (since there is more at stake) and the replacement rate $\imath+\mu$ (the instantaneous probability of full capital loss at each point in time), and it decreases with $w_{H N \gamma}$ (the unit cost of RPAs). ${ }^{17}$

\footnotetext{
${ }^{17}$ It should be noted that one can also obtain (17) by maximizing the steady-state market value of the firm with respect to $X$. This involves plugging in $\iota(X), \mu(X)$ and $\pi_{N}$ from (7) into (15) and then setting $\partial v_{N} / \partial X=0$. Hence, from a methodological point of view, maximizing the stock market value of the firm
} and maximizing the expected return on the stocks are equivalent. 


\subsection{Labor markets}

Since one unit of production goods of any quality is produced by one unit of labor, the Northern demand for manufacturing labor is given by the proportion of Northern industries $n_{N}$ times the quantity of consumption goods produced for the North and the South, respectively. From our results of Section 2.3, this is $n_{N}\left\{c_{N} N_{N} /\left[\lambda\left(1+\tau_{N}\right)\right]+c_{S} N_{S} / \lambda\right\}$. The Northern demand for R\&D labor is $a_{t} R=a_{l} l D$, where (9) is used. Thus the Northern general-purpose labor market clearing $(L A B N)$ condition is

$$
n_{N} Q_{N}\left(c_{N}, c_{S}\right) N_{N}+a_{l} l D=\left(1-s_{N}\right) N_{N} \quad \text { with } \quad Q_{N}\left(c_{N}, c_{S}\right) \equiv \frac{1}{\lambda}\left(\frac{c_{N}}{1+\tau_{N}}+c_{S} \eta_{S}\right)
$$

where $Q_{N} N_{N}$ denotes the aggregate production of a Northern incumbent firm, and $\eta_{S} \equiv N_{S} / N_{N}$ measures the relative size of the South. The Northern specialized labor market clearing condition is

$$
n_{N} \gamma X=s_{N} N_{N} .
$$

The Southern demand for manufacturing labor is given by the proportion of Southern industries $n_{S}$ times the quantity of consumption goods produced for the North and the South, respectively. From our results of Section 2.3, this is $n_{S}\left\{c_{S} N_{S}\right\}$ $\left.\left[w_{L N}\left(1+\tau_{S}\right)\right]+c_{N} N_{N} / w_{L N}\right\}$. The Southern demand for R\&D labor is $n_{N} a_{\mu} M=n_{N} a_{\mu} \mu D$, where (12) is used. Thus the Southern labor market clearing $(L A B S)$ condition is

$$
n_{S} Q_{S}\left(c_{N}, c_{S}, w_{L N}\right) N_{N}+a_{\mu} \mu D n_{N}=N_{S} \quad \text { with } \quad Q_{S}\left(c_{N}, c_{S}, w_{L N}\right) \equiv \frac{1}{w_{L N}}\left(\frac{c_{S} \eta_{S}}{1+\tau_{S}}+c_{N}\right),
$$

where $Q_{S} N_{N}$ denotes the aggregate production of a Southern incumbent firm.

\subsection{Steady-state equilibrium}

Northern (Southern) entrepreneurs capture industry leadership from Southern (Northern) firms at a rate of $i n_{S}\left(\mu n_{N}\right)$, and constancy of industry shares requires $\iota n_{S}=\mu n_{N}$. Given $n_{N}+n_{S}=1$, this implies

$$
n_{S}=\mu /(l+\mu) \text { and } n_{N}=l /(l+\mu) \text {. }
$$

Let $A_{l} \equiv\left(a_{l} \delta\right) /(n \gamma)$ and $A_{\mu} \equiv\left(a_{\mu} \delta\right) /(n \gamma)$, which capture the resource requirement in innovative and imitative R\&D relative to RPAs, respectively. We solve the model for a steady-state equilibrium where the endogenous variables $c_{N}, c_{S}, l, \mu, w_{L N}$ and $w_{H N}$ remain constant, and $R, M, \pi_{N}, \pi_{S}, X, v_{N}$ and $v_{S}$ all grow at common rate of $n$. We impose a balance-of-trade (BOT) condition, which requires that the value of exports net of tariffs be equal between the North and the South ${ }^{18}$ :

$$
n_{N} \frac{c_{S} N_{S}}{\lambda} \frac{\lambda}{\left(1+\tau_{S}\right)}=n_{S} \frac{c_{N} N_{N}}{w_{L N}} \frac{w_{L N}}{\left(1+\tau_{N}\right)}
$$

where the LHS (RHS) denotes the value of Northern (Southern) exports net of tariffs. This can be rewritten, by using (21), as

$$
c_{S}=c_{N} \frac{\mu}{l \eta_{S}} \frac{\left(1+\tau_{S}\right)}{\left(1+\tau_{N}\right)} \quad \operatorname{BOT}\left(c_{S}, c_{N}, l, \mu\right)
$$

which determines the relative consumer expenditure levels for both countries.

Substituting in (17) for $v_{N}$ from (13), then for $D$ from (10) and finally for $n_{N}$ from (21), we obtain the Northern specialized wage rate as

$$
W_{H N}=A_{l} l w_{L N},
$$

implying that $w_{H N} / w_{L N}$ is increasing in $\imath$. This is because a higher innovation rate increases the profitability of RPAs relative to innovation and thus $w_{H N} / w_{L N}$.

Plugging (17) into (7), using (5), and inserting all this into (15), using the steady-state results $r_{t}=\rho$ and $\dot{v}_{N} / v_{N}=n$, we solve for the stock-market value of Northern firms as

$$
v_{N}=\frac{c_{N} N_{N}\left\{1-\left[w_{L N} / \lambda\left(1+\tau_{N}\right)\right]\right\}+c_{S} N_{S}\left\{\left[1 /\left(1+\tau_{S}\right)\right]-\left(w_{L N} / \lambda\right)\right\}}{\rho-n+2(l+\mu)} .
$$

Setting (24) equal to (13), substituting for $D$ from (10), then for $X n_{N}$ from (19), using the definitions of $A_{l}$ and $\eta_{S}$, and imposing the BOT condition (22), we obtain the free-entry in innovation (FEIN) condition, which equates discounted

${ }^{18}$ As an alternative approach, Appendix R.2 (available upon request) considers the steady-state solution with an asset market equilibrium condition instead of a BOT condition. It turns out that this leads to exactly the same conclusions regarding the globalization effects on the main variables of interest. 
innovative $R \& D$ benefits and current innovative R\&D costs:

$$
\frac{c_{N}\left\{1+\left[\mu / l\left(1+\tau_{N}\right)\right]\right\}-\tilde{Q}_{N}\left(c_{N}\right) w_{L N}}{\rho-n+2(l+\mu)}=A_{l} w_{L N} S_{N} \quad \operatorname{FEIN}\left(c_{N}, w_{L N}, l, \mu\right) .
$$

where $Q_{N}\left[c_{N}, c_{S}\left(c_{N}\right)\right] \equiv \tilde{Q}_{N}\left(c_{N}\right)=\frac{c_{N}}{\lambda\left(1+\tau_{N}\right)}\left[1+\frac{\mu\left(1+\tau_{S}\right)}{l}\right]$ by using (22). Analogously, by setting (14) equal to (16), and using (6), (10), (19), and (22), we obtain the free-entry in imitation (FEIM) condition which equates discounted imitative R\&D benefits and current imitative R\&D costs:

$$
\frac{\overbrace{\left[c_{N} /\left(1+\tau_{N}\right)\right]\left\{1+\left[\mu\left(1+\tau_{S}\right) / l\right]\right\}}^{\lambda \tilde{Q}_{N}\left(c_{N}\right)}-\tilde{Q}_{S}\left(c_{N}, w_{L N}\right)}{\rho-n+l}=A_{\mu} s_{N} \quad \operatorname{FEIM}\left(c_{N}, w_{L N}, l, \mu\right),
$$

where $Q_{S}\left[c_{N}, c_{S}\left(c_{N}\right), w_{L N}\right] \equiv \tilde{Q}_{S}\left(c_{N}, w_{L N}\right)=\frac{c_{N}}{w_{L N}}\left[1+\frac{\mu}{l\left(1+\tau_{N}\right)}\right]$ by using $(22)$.

For given $l$ and $\mu$, the FEIN and FEIM conditions determine a unique steady-state solution for $c_{N}$ and $w_{L N}$ as shown in Fig. 2 below.

The FEIN curve as implied by (25) is upward sloping in $\left(c_{N}, w_{L N}\right)$ space because a higher $w_{L N}$ reduces R\&D profitability by increasing both production and R\&D costs in the North. Restoring the zero-profit condition for innovation requires an increase in $c_{N}$. The FEIM curve as implied by (26) is downward sloping in $\left(c_{N}, w_{L N}\right)$ space because a higher $w_{L N}$ raises imitation profitability by raising the limit price successful Southern followers can charge both in the Northern and in the Southern market. Restoring the zero-profit condition for imitation requires a decrease in $c_{N}$. Solving (25) and (26) simultaneously for $c_{N}$ and $w_{L N}$ yields

$$
\begin{aligned}
& c_{N}(l, \mu)=\frac{l s_{N} \lambda\left(1+\tau_{N}\right)\left\{A_{l}[\rho-n+2(l+\mu)]+A_{\mu}(\rho-n+l)\right\}}{(\lambda-1)\left[l+\mu\left(1+\tau_{S}\right)\right]} . \\
& w_{L N}(l, \mu)=\frac{\lambda\left\{A_{l}[\rho-n+2(l+\mu)]+A_{\mu}(\rho-n+l)\right\}\left[l\left(1+\tau_{N}\right)+\mu\right]}{\left\{\lambda A_{l}[\rho-n+2(l+\mu)]+A_{\mu}(\rho-n+l)\right\}\left[l+\mu\left(1+\tau_{S}\right)\right]} .
\end{aligned}
$$

Dividing (25) by (26) and simplifying gives

$$
\frac{l\left(1+\tau_{N}\right)+\mu-\left(w_{L N} / \lambda\right)\left[l+\mu\left(1+\tau_{S}\right)\right]}{w_{L N}\left[l+\mu\left(1+\tau_{S}\right)\right]-l\left(1+\tau_{N}\right)-\mu} \frac{(\rho-n+l)}{[\rho-n+2(l+\mu)]}=\frac{A_{l}}{A_{\mu}} .
$$

This ratio essentially summarizes the relative profitability condition between innovation and imitation. The LHS captures the profit margins for innovators relative to imitators and the RHS captures the cost of innovation relative to imitation. Hence, a reduction in the Northern tariff rate $\tau_{N}$ reduces the profitability of innovation relative to imitation. Restoring the free-entry conditions for given $l$ and $\mu$ requires a decrease in $w_{L N}$, which increases innovation profitability (by raising the innovators' profit margins and reducing their R\&D costs) and reduces imitation profitability (by reducing the imitators' limit prices and thus their profit margin). A reduction in the Southern tariff rate $\tau_{S}$ causes the opposite effects by increasing the profitability of innovation relative to imitation. We summarize our findings as:

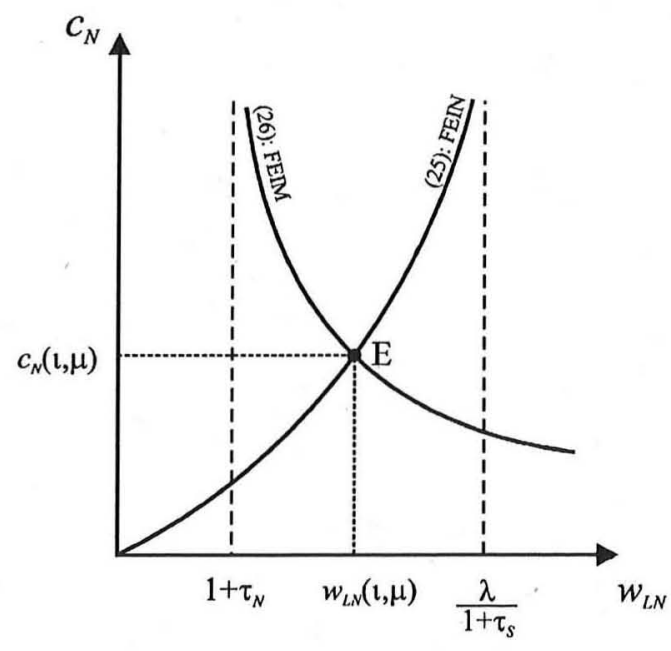

Fig. 2. The determination of $c_{N}(l, \mu)$ and $w_{L N}(l, \mu)$. 


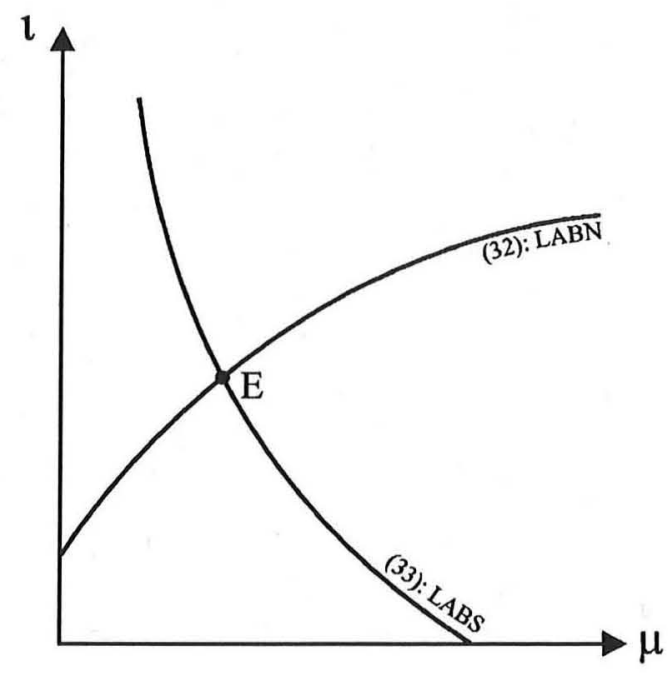

Fig. 3. The steady-state equilibrium.

Lemma 1. Independently of $c_{N}$, the North-South general-purpose relative wage gap $w_{L N} / w_{S} \equiv w_{L N}$ is increasing in the profitability of innovation relative to imitation.

Using (10) and (19), we find $D=s_{N} N_{N} \delta /(\gamma n)$. Using this, (21) and the expression for $\tilde{Q}_{N}$, the LABN condition (18) can be rewritten as

$$
\frac{\tilde{Q}_{N}\left(c_{N}\right) l}{l+\mu}+A_{l} l s_{N}=1-s_{N} \quad \operatorname{LABN}\left(c_{N}, l, \mu\right)
$$

Similarly, by using $D=s_{N} N_{N} \delta /(\gamma n)$, (21) and the expression for $\tilde{Q}_{S}$, the LABS condition (20) can be rewritten as

$$
\frac{\tilde{Q}_{S}\left(c_{N}, w_{L N}\right) \mu}{\eta_{S}(l+\mu)}+\frac{A_{\mu} \mu s_{N}}{\eta_{S}} \frac{l}{(l+\mu)}=1 \quad L A B S\left(c_{N}, w_{L N}, l, \mu\right) .
$$

Using (27) in (30) gives the Northern labor market equilibrium condition as a function solely in $l$ and $\mu$ :

$$
\frac{\imath s_{N}\left\{A_{t}[\rho-n+(l+\mu)(1+\lambda)]+A_{\mu}(\rho-n+l)\right\}}{(\lambda-1)(l+\mu)}=1-s_{N} \quad \operatorname{LABN}(l, \mu),
$$

which does not depend on the tariff rates. The LHS of (32) is strictly increasing in $t$ and strictly decreasing in $\mu$ (since $\rho-n>0)$, hence the curve for LABN is strictly upward sloping in $(l, \mu)$ space. Intuitively, an increase in $l$ raises Northern general-purpose labor demand for R\&D and for manufacturing by raising both $n_{N}$ and $c_{N}$, where the latter follows from $\partial c_{N} /$ $\partial l>0$ in (27). Restoring the Northern labor market equilibrium requires an increase in $\mu$ since this reduces Northern labor demand by decreasing both $n_{N}$ and $c_{N}$, where the latter follows from $\partial c_{N} / \partial \mu<0$ in (27). ${ }^{19}$

Using (27) and (28) in (31) gives the Southern labor market equilibrium condition as a function solely in $\iota$ and $\mu$ :

$$
\frac{\mu s_{N}\left\{A_{l} \lambda[\rho-n+2(l+\mu)]+A_{\mu}(\rho-n+l \lambda)\right\}}{\eta_{S}(\lambda-1)(l+\mu)}=1 \quad \operatorname{LABS}(l, \mu),
$$

which also does not depend on the tariff rates. The LHS of (33) is strictly increasing in $\mu$, while it is strictly increasing in $\iota$ provided that the following condition is satisfied, which will be maintained for the rest of this paper:

$$
\mu>(\rho-n)\left(\frac{1}{\lambda}+\frac{A_{l}}{A_{\mu}}\right) \text {. }
$$

This amounts to the assumption that the households' net discount rate $\rho-n$ is sufficiently small. Given that condition (34) is satisfied, the curve for LABS is strictly downward sloping in $(l, \mu)$ space such that the steady-state equilibrium illustrated in Fig. 3

\footnotetext{
${ }^{19}$ To uncover the underlying mechanisms for $\partial c_{N} / \partial t>0$ and $\partial c_{N} / \partial \mu<0$ we use (25), (26), and Fig. 2. A higher $l$ increases the pace of creative destruction and also leads to lower $c_{S}$ for a given $c_{N}$ through the BOT condition (the reason is that a higher $\imath$ reduces the fraction of Southern industries $n_{S}$ and leads to lower Southern consumption expenditure). Thus, the rewards from both innovation and imitation decline. Restoring equilibrium requires an increase in $c_{N}$, shifting both the FEIN and FEIM curves up in Fig. 2. For the case of an increase in $\mu$ the opposite shifts are observed. A higher $\mu$ increases the pace of replacement for Northern innovators but at the same time leads to higher $c_{S}$ through the BOT condition (the reason being an increase in $n_{S}$ ). In the neighborhood of zero tariffs, the net impact implies higher rewards from innovation. Simultaneously, the higher $\mu$ increases the rewards from imitation through the increased $c_{S}$ effect without exerting a replacement effect for Southern imitators. With both innovation and imitation profitability increased, restoring equilibrium requires a decrease in $c_{N}$, which shifts both the FEIN and FEIM curves down in Fig. 2.
} 
above is unique. ${ }^{20}$ An increase in $\mu$ raises the labor demand for Southern manufacturing by increasing both $n_{S}$ and $c_{N}$. This is reinforced by the lower $w_{L N}$ which is triggered by an increase in $\mu$. To see this, differentiate (28) with respect to $\mu$. The lower $w_{L N}$ increases Southern production employment because it reduces the limit prices successful Southern imitators can charge in both the Southern and the Northern markets, which in turn raises consumption demand and hence production. In addition, an increase in $\mu$ directly increases Southern R\&D labor demand by raising the Southern economy-wide imitation rate $m \equiv \mu n_{N}$.

Restoring the Southern labor market equilibrium requires a decrease in $l$, which has four effects on Southern labor demand: first, it reduces Southern R\&D labor demand by reducing the Southern economy-wide imitation rate $m \equiv \mu n_{N}$. Second, it increases $w_{L N}$ provided that both tariff rates are sufficiently low and $\mu>(\rho-n) / 2$. To see this, differentiate (28) with respect to $l$. An increase in $w_{L N}$ raises the limit prices (in both countries) charged by successful Southern imitators and hence reduces Southern production employment. Third, a decrease in $l$ raises $n_{S}$, which tends to increase Southern production employment. Fourth, a decrease in $\imath$ has an ambiguous effect on $c_{s}$. The net effect is a decrease in total Southern labor demand provided that (34) is fulfilled.

Finally, from (2) we can derive as usual the common steady-state utility growth rate of both countries, which is $\dot{u}_{N} / u_{N}=\dot{u}_{S} / u_{S}=\imath \log \lambda .^{21}$

\section{Globalization effects}

\subsection{Increased trade integration of the South}

We first consider the effects of increased trade integration of the South, modeled as an increase in the relative size of the South $\eta_{S} \equiv N_{S} / N_{N}{ }^{22}$ This exercise is motivated by the recent entry of large developing countries into the world trading system. Using the Sachs and Warner openness criteria, Wacziarg and Welch (2008) calculate that between 1980 and 2000 , the percentage of open economies had increased from about $26 \%$ to $73 \%$. During the same time period, the percentage of the world population living in open economies has increased from about $25 \%$ to $46 \%$. The discrepancy between the two measures stems from the fact that China and India, the world's two most populous countries, were still classified as closed economies as of year 2000 in Wacziarg and Welch (2008). However, it is well known that these two countries have made substantial progress towards trade liberalization and appear to be on their way to meeting the Sachs and Warner openness criteria.

An expansion in the relative size of the Southern market $\eta_{S}$ leaves the free-entry conditions (25) and (26) unaffected. Thus the FEIN and FEIM curves in Fig. 2 remain the same. This is because the BOT condition (22) requires a constant ratio of Southern to Northern consumption expenditure $c_{S} N_{S} /\left(c_{N} N_{N}\right)=\mu\left(1+\tau_{S}\right) /\left[\imath\left(1+\tau_{N}\right)\right]$ for given levels of $l$ and $\mu$. Hence, the profit flows of Northern innovators and Southern imitators are independent of $\eta_{s}$. The LABN curve (32) of Fig. 3 is not affected either. To see this, first note again by the BOT condition that total expenditure by Southern consumers is proportional to that by Northern consumers. Thus, Northern exports $n_{N} c_{S} N_{S} / \lambda$ are proportional to $N_{N}$. Second, the levels of Northern production for domestic consumption and innovation difficulty $D$ are also proportional to $N_{N}$. With the aggregate Northern labor supply given by $N_{N}$, it follows that the $N_{N}$ terms in the LABN equation cancel out. Thus, changes in relative market size $\eta_{S} \equiv N_{S} / N_{N}$ exert no direct influence on the LABN condition.

In the South, using again the BOT condition, we observe that Southern production for domestic consumption $n_{S} c_{S} N_{S} /$ $\left[\left(1+\tau_{S}\right) w_{L N}\right]$ is proportional to $N_{N}$. The levels of Southern exports and imitation difficulty $D$ are also proportional to $N_{N}$. Hence, in the South, aggregate labor demand is proportional to $N_{N}$, whereas aggregate labor supply is obviously proportional to $N_{S}$. Therefore a higher $\eta_{S}$ creates room for an expansion in both imitative and manufacturing activities, resulting in a larger $\mu$ for a given $t$. Consequently, the LABS curve shifts to the right, and the equilibrium rates of both $\mu$ and $\iota$ increase. The intuition can be understood by appealing to the upward sloping LABN curve. When $\mu$ increases, Northern manufacturing labor demand falls due to the decrease in $n_{N}$ and $c_{N}$. Restoring equilibrium calls for an increase in $l$, which boosts both R\&D and manufacturing labor demand in the North. The result is shown in Fig. 4 below.

To investigate the change in $w_{L N}$, we use the relative profitability ratio given in (29). With the rise in the equilibrium level of $\mu$, Northern firms face a stronger imitation threat from the South. Hence, the profitability of innovation relative to imitation declines. At the same time, the higher equilibrium level of $l$ increases the replacement rate of firms in all industries, thereby reducing the rewards to both innovators and imitators. This raises the profitability of innovation relative

\footnotetext{
${ }^{20}$ Existence of the steady-state equilibrium is ensured by noting that, first, the LABS curve (33) cannot hit the vertical axis since (34) guarantees $\mu>0$ $\forall \imath$ on LABS, second, the LABN curve (32) for $\mu \rightarrow 0$ clearly starts at some $\imath>0$, and third, the LABN curve is concave in $\mu$. The latter is easily verified by applying the implicit function theorem to (32), which gives $\frac{\partial t}{\partial \mu}=\frac{1\left[A_{t}(\rho-n)+A_{\mu}(\rho-n+1)\right]}{\mu\left\{A_{t}[\rho-n+(1+\mu)(1+\lambda)]+A_{\mu}(\rho-n+t)\right\}+(1+\mu) !\left[A_{t}(1+\lambda)+A_{\mu}\right]}>0$.

21 Details of the derivation can be found in Appendix R.3, which is available from the authors upon request.

22 When one investigates the consequences of North-South integration, the issue of scale effects becomes especially important. In scale-dependent product cycle models like Grossman and Helpman (1991), changes in one region's population size can affect the steady-state rates of innovation or imitation even if that region's share in the world economy remains the same. Scale-free product cycle models like this one do not have this questionable feature. Instead, steady-state outcomes depend on relative population sizes; that is, an expansion in the absolute size of the South generates the same qualitative steady-state effects as does a contraction in the absolute size of the North, and vice versa.
} 


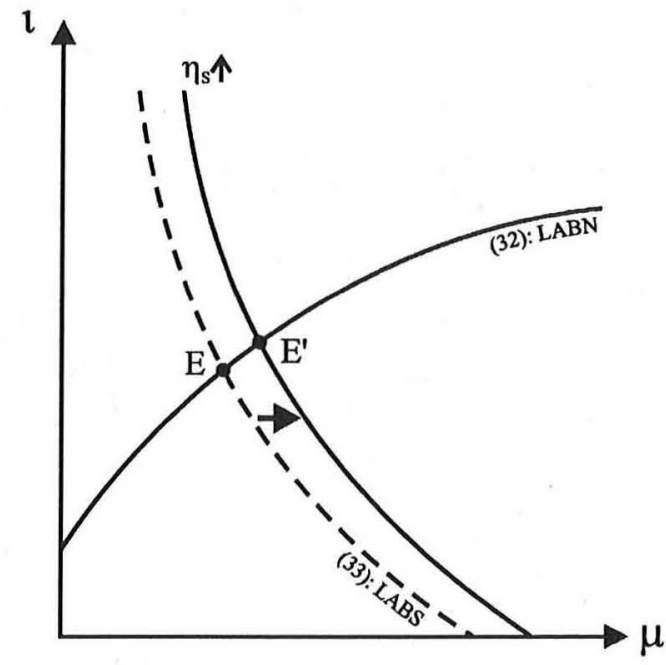

Fig. 4. Steady-state effects of increased Southern trade integration.

to imitation if and only if $\mu>(\rho-n) / 2$. Hence, the increase in $l$ can cause a countervailing effect on relative innovation-imitation profitability. Nevertheless, for sufficiently low tariffs, we find that the impact coming from $\mu$ dominates all other effects and the profitability of innovation relative to imitation declines. ${ }^{23}$ It then follows from Lemma 1 that the relative wage of Northern general-purpose labor $w_{L N}$ declines as well. Furthermore, we can also establish $d n_{N} / d \eta_{S}<0$ and $d m / d \eta_{s}>0 .{ }^{24}$ The proportion of Northern industries $n_{N}$ decreases since the resulting increase in $\mu$ more than outweighs the resulting increase in $t$. The aggregate Southern imitation rate $m=\mu n_{N}$ increases since the resulting increase in the industry-wide imitation rate $\mu$ more than outweighs the resulting decrease in $n_{N}$. The effects of increased Southern trade integration are summarized in

Proposition 1. Given that (34) is fulfilled, a unique steady-state equilibrium exists, and increased Southern trade integration (i.e. an increase in $\eta_{s}$ ) results in

i. an increase in the Northern innovation rate $l$ and hence in the steady-state utility growth rate of both countries,

ii. an increase in the frequency of imitations per industry $\mu$,

iii. an increase in the economy-wide Southern imitation rate $m \equiv \mu n_{N}$, and

iv. a decrease in the fraction of the Northern industries $n_{N}$.

For sufficiently low $\tau_{N}$ and $\tau_{S}$, it also results in

v. a decrease in the relative Northern general-purpose wage rate $w_{L N}$.

\subsection{Unilateral trade liberalization}

Since tariffs do not enter Eqs. (32) and (33), a decrease in $\tau_{N}$ or $\tau_{S}$ does not affect the curves in Fig. 3, and $\imath$ and $\mu$ remain unchanged. We begin with the technical analysis for $\tau_{N}$. First, note that $c_{N} /\left(1+\tau_{N}\right)$ is pinned down by $l$ and $\mu$ in (27) independently of $\tau_{N}$. It then follows that the $\tilde{Q}_{N}$ expression stated below (25) is also determined by $l$ and $\mu$ independently of $\tau_{N}$. Given this, we observe from the FEIM condition (26) that the $\tilde{Q}_{S}$ expression becomes a function of $\iota$ and $\mu$ again independent of $\tau_{N}$. With manufacturing levels not responding to Northern tariff changes, we immediately see from the labor market conditions (30) and (31) that the industry-wide rates of innovation and imitation $l$ and $\mu$ are neutral to variations in $\tau_{N}$.

To uncover the intuition, we analyze the FEIN and FEIM conditions holding $\imath$ and $\mu$ constant. First, a lower $\tau_{N}$ reduces the extent of protection granted to Northern firms in the domestic market. This cuts into their profit margins, forcing them to reduce their limit price $p_{N}^{N}$ and thus their profits in the Northern market $\pi_{N}^{N}$ decline. Second, a lower $\tau_{N}$ leads to a higher $c_{S}$ through the BOT condition (22) and thus increases the Northern firms' profits in the Southern market $\pi_{N}^{S}$. To see this, note that a fall in $\tau_{N}$ increases the net-of-tariff price enjoyed by the Southern exporters, $w_{L N} /\left(1+\tau_{N}\right)$, implying a Southern Termsof-Trade (TOT) improvement. Through the BOT condition, the improved Southern TOT allows for a higher Southern

\footnotetext{
${ }^{23}$ This restriction means that we are able to formally establish this result for $\tau_{N}=\tau_{S}=0$, but obviously it holds for a full range of tariff rates, although the exact upper boundaries cannot be determined. These boundaries are consistent with our assumptions $\tau_{N}<w_{L N}-1$ (which is necessary to ensure $\left.\pi_{S}^{N}>0\right)$ and $\tau_{S}<\left(\lambda / w_{L N}\right)-1$ (which is necessary to ensure $\pi_{N}^{S}>0$ ).

24 For proofs, see Appendix A
} 
per-capita expenditure $c_{S}$. With $\pi_{N}^{N}$ decreasing and $\pi_{N}^{S}$ increasing, the net impact on Northern innovation profitability is ambiguous. Thus, the FEIN curve may shift up or down.

For the Southern imitators, the TOT improvement directly raises the profit margins on exports and thus leads to higher profits realized in the Northern market $\pi_{S}^{N}$. In addition, the higher $c_{S}$ raises domestic market sales and thereby increases the profits in the Southern market $\pi_{S}^{S}$. As a result, Southern imitation profitability clearly increases. To restore equilibrium, $c_{N}$ must decrease and the FEIM curve shifts down.

By differentiating (27) and (28), we conclude that for given levels of $\iota$ and $\mu$, the fall in $\tau_{N}$ reduces both $c_{N}$ and $w_{L N}$. To examine the change in $c_{S}$, we analyze the BOT condition (22), which implies that $c_{S}$ decreases due to the fall in $c_{N}$ and increases due to the fall in $\tau_{N}$. Substituting for $c_{N}$ from (27) into (22) reveals that the two effects exactly cancel out and there is no change in $c_{S}$.

We note the fall in $c_{N}$ and $w_{L N}$ for given levels of $\imath$ and $\mu$ and now analyze the labor markets. In the North, the lower $c_{N}$ reduces the demand for labor (by decreasing sales and thus production) and the lower tariff $\tau_{N}$ increases it (by reducing product prices and boosting production). As noted above, the Northern firm's aggregate production $Q_{N} N_{N}$ is independent of $\tau_{N}$; thus, the two effects cancel out, leaving the LABN equation unaffected. In the South, the lower $c_{N}$ reduces the demand for labor (again via reduced sales) and the lower $w_{L N}$ increases the demand for labor (again via lower prices). Since the Southern firm's aggregate production $Q_{S} N_{N}$ is independent of $\tau_{N}$, the two effects cancel out and the LABS equation remains unaffected.

The technical analysis for $\tau_{S}$ is very similar. First, note that from (27) and (28), the ratio $c_{N} / w_{L N}$ is independent of $\tau_{S}$. It then follows that the $\tilde{Q}_{S}$ expression stated below (26) is also a function of $\imath$ and $\mu$ independent of $\tau_{s}$. Given this, we observe from the FEIM condition (26) that $\tilde{Q}_{N}$ is also pinned down by $l$ and $\mu$ independently of $\tau_{s}$. With manufacturing levels not responding to Southern tariff changes, we immediately note from the labor market conditions (30) and (31) that $l$ and $\mu$ are neutral to variations in $\tau_{S}$. The economic intuition can be uncovered via the same mechanisms as used for a decrease in $\tau_{N}$.

To investigate the change in the equilibrium relative wage $w_{L N}$, we note that the equilibrium levels of $l$ and $\mu$ remain unchanged: thus the decline in $w_{L N}$ established by the shifts in FEIN and FEIM curves remain intact. The intuition is that a lower $\tau_{N}$ decreases the Northern firm's profit margin but increases the Southern firm's profit margin, as implied by (29). This leads to a fall in the profitability of innovation relative to imitation and it follows from Lemma 1 that $w_{L N}$ decreases. The opposite is true for a decline in $\tau_{s}$. We summarize our findings in

Proposition 2. Given that (34) is fulfilled, a unique steady-state equilibrium exists, and a reduction in the Southern [Northern] import tariff $\tau_{S}\left[\tau_{N}\right]$ results in

i. no change in the Northern innovation rate $\mathrm{l}$ or the frequency of imitations per industry $\mu$, and therefore also no change in the fraction of the Northern industries $n_{N}$ and the economy-wide Southern imitation rate $m \equiv \mu n_{N}$ ('tariff-neutrality result'), ii. an unambiguous increase [decrease] in the Northern general-purpose wage rate $w_{L N}$.

We conclude that in our two-country monopolistic competition setting with a symmetric production and trade structure, and with consumption expenditure being proportional to tariffs by balanced trade, firm-level aggregate production $Q_{N} N_{N}$ and $Q_{S} N_{N}$ are independent of tariffs. The mechanism for this result follows from the three main conditions of the model: balanced trade, and free-entry in innovation and imitation. Consequently, changes in tariffs do not call for any reallocation between manufacturing and innovation or imitation. It should be noted that this neutrality result also holds with CES consumer preferences and monopolistic pricing, as is shown by Dinopoulos and Segerstrom (2007) in a setting with symmetric iceberg trade costs instead of tariffs.

\section{Variations of the basic model}

\subsection{Increased Southern trade integration with Southern specialized labor}

How robust are the findings to incorporating Southern institutions that require employment of Southern resources for imitation-deterring activity? To check for this, we now assume that Northern firms hire Northern specialized labor for innovation-deterring activity, and Southern specialized labor for imitation-deterring activity, the latter being paid the Southern specialized wage rate $w_{H S}$. We denote the level of imitation (innovation)-deterring activities $X_{\mu}\left(X_{l}\right)$ with corresponding unit labor requirement $\gamma_{\mu}\left(\gamma_{1}\right)$, and the share of specialized labor in the South is given by $s_{s}$. Innovation and imitation difficulty evolve according to $\dot{D}_{l}=n_{N} \delta_{l} X_{l}$ and $\dot{D}_{\mu}=n_{N} \delta_{\mu} X_{\mu}$, respectively. On the steady-state growth path, $\dot{D}_{l} / D_{l}=\dot{D}_{\mu} / D_{\mu}=n$. This, together with the new Southern specialized-labor market-clearing condition $n_{N} \gamma_{\mu} X_{\mu}=s_{S} N_{S}$ implies $D_{\mu}=\left(s_{S} N_{S} \delta_{\mu}\right) /\left(\gamma_{\mu} n\right)$.

The FEIN condition (25) remains the same (with only $\hat{A}_{l} \equiv\left(a_{l} \delta_{l}\right) /\left(n \gamma_{l}\right)$ replacing $\left.A_{l}\right)$, whereas the RHS of the FEIM condition (26) becomes $\hat{A}_{\mu} s_{s} \eta_{s}$, with $\hat{A}_{\mu} \equiv\left(a_{\mu} \delta_{\mu}\right) /\left(n \gamma_{\mu}\right)$. Using this notation and $D_{\mu}$ from above, we present the new reduced-form equations for $\operatorname{LABN}(l, \mu)$ and $\operatorname{LABS}(l, \mu)$ in Appendix $\mathrm{B}$. As before, the LABN curve is upward sloping and the LABS curve is downward sloping. To simplify the exposition, we set $\tau_{N}=\tau_{S}=0$. 
To investigate the impact of increased Southern trade integration, we first note that an increase in $\eta_{S}$ does not affect the FEIN curve but shifts the FEIM curve upwards in Fig. 2, hence both $c_{N}$ and $w_{L N}$ increase for given levels of $l$ and $\mu$. Intuitively, an increase in $\eta_{s}$ now renders more resources available for imitation-deterring activities and reduces the profitability of imitation. Restoring the free-entry condition requires an increase in $c_{N}$ and hence an upward shift of the FEIM curve.

Next, to uncover the labor-market implications, we write the new labor market equilibrium conditions as ${ }^{25}$

$$
\begin{aligned}
& \frac{c_{N}\left(l, \mu, \eta_{S}\right)}{\lambda}+\hat{A}_{l} l s_{N}=1-s_{N} \quad \operatorname{LABN}(l, \mu), \\
& \frac{c_{N}\left(l, \mu, \eta_{S}\right) \mu}{w_{L N}\left(l, \mu, \eta_{S}\right) l}+\frac{\hat{A}_{\mu} \mu s_{S} l \eta_{S}}{l+\mu}=\left(1-s_{S}\right) \eta_{S} \quad \operatorname{LABS}(l, \mu),
\end{aligned}
$$

where the new solutions for $w_{L N}$ and $c_{N}$ are given in (B.4) and (B.5), respectively.

In the South, an increase in $\eta_{S}$ raises the (relative) Southern labor supply and also labor demand via two channels. First, an increase in $\eta_{S}$ raises the intensity of imitation-deterring activity per Northern worker $D_{\mu} / N_{N}$, and thereby increases the resource requirement for imitation. Second, a higher $\eta_{S}$ leads to an expansion in Southern manufacturing activity (formally, $\partial\left(c_{N} / w_{L N}\right) / \partial \eta_{S}>0$, see Eq. (B.6)) and puts more pressure on Southern resources. The direct increase in labor supply outweighs the increase in labor demand, creating room to expand imitation for any given $l$, which explains the rightward shift of the LABS curve as in Fig. 4 before.

In the North, the increases in $c_{N}$ triggered by the increase in $\eta_{S}$ leads to an expansion in Northern manufacturing. To restore equilibrium in (35), there must be a decline in $\imath$ for a given $\mu$, and hence the LABN curve shifts down (recall that aggregate labor demand in the North is increasing in 1 ). This is a new effect relative to the analysis illustrated in Fig. 4 for the case of general RPAs performed only by Northern specialized workers. Hence, contrary to the basic setting in Section 3.1, the net effect of increased Southern trade integration on the Northern innovation rate $\imath$ becomes ambiguous, ${ }^{26}$ whereas the Southern industry-wide imitation rate $\mu$ again increases.

To investigate the change in $w_{L N}$, we focus on the FEIN to FEIM ratio (B.3), which captures the relative innovation-imitation profitability. An increase in $\eta_{S}$ now exerts a direct effect on innovation profitability by raising the amount of resources channeled to imitation-deterring activities (captured by the $\hat{A}_{\mu} s_{S} \eta_{S}$ term on the RHS of FEIM, see (B.2)). This raises $D_{\mu} / D_{l}$ and implies an increase in the cost of imitation relative to innovation. ${ }^{27}$ Thus, the direct effect works towards increasing the profitability of innovation relative to imitation. Simultaneously, as in the baseline model, there are two other effects. One is triggered by the increase in $\mu$ which works to decrease relative innovation profitability (as it increases the threat of replacement for innovators, but not for imitators) and the other is an ambiguous effect stemming from the ambiguous change in $t$. Despite the presence of other effects, we find that the decisive force is the direct effect, and the profitability of innovation relative to imitation increases. It then follows from Lemma 1 that $w_{L N}$ increases (see Appendix B for formal proof). Observe that this is the exact opposite of our finding from the baseline model where the effect of the increase in $\mu$ was the decisive force and caused a decrease in relative profitability of innovation and therefore a fall in $w_{L N}$. It follows our

\section{Main Result 1}

When the institutional set-up requires Southern resources to be employed for imitation-deterring activities, increased Southern trade integration will bring forth an expansion in imitation-deterring activities as well. Relative to the baseline model, this

i. will reverse the (negative) effect of increased Southern trade integration on the Northern general-purpose wage rate $w_{L N}$ and ii. can reverse the (positive) effect of increased Southern trade integration on the Northern innovation rate 1 and thus global growth.

To shed further light on the differential response of $l$, we analyze the impact on the absolute profitability of innovation. In both the baseline model, and the model with Southern-resource-using RPAs an increase in the relative size of the South $\eta_{S}$, as expected, generates an expansion in the imitation activities undertaken by the South, raising the frequency of imitations per industry $\mu$. The higher imitation exposure shortens the duration of monopoly power for successful Northern innovators and induces them to intensify their imitation-deterring expenditures (note that the additional $l+\mu$ term in the discount

\footnotetext{
${ }^{25}$ Equation (35) follows from (30) by using the definition of $\tilde{Q}_{N}$ from the line below (25), setting $\tau_{N}=\tau_{S}=0$, and replacing $A_{1}$ by $\hat{A}_{1}$. Similarly, Eq. (36) follows from (31) by using the definition of $\tilde{Q}_{S}$ from the line below (26), setting $\tau_{N}=0$, and replacing $A_{\mu}$ by $\hat{A}_{\mu}$ and (since now Southern workers are used for imitation-deterring activities) $s_{N}$ by $s_{S} \eta_{S}$ on the LHS, and $\eta_{S}$ by $\left(1-s_{S}\right) \eta_{S}$ on the RHS.

${ }^{26}$ Indeed, for a sufficiently low consumer discount rate $\rho-n$, one can show that the net impact on, becomes unambiguously negative, see Appendix B.

${ }^{27}$ Note the crucial difference to the baseline setting: with only general RPAs in the North, Southern R\&D difficulty cannot increase relative to Northern R\&D difficulty since these are identical by assumption.
} 
factor of FEIN captures the impact of total rent protection costs on firm value). Clearly, in both settings, these two forces decrease the stock market valuation of Northern innovators and adversely affect innovation incentives in the North.

In the baseline model, the decline in $w_{L N}$ more than compensates for the reduced innovation incentives by reducing both $R \& D$ and production costs. Hence the equilibrium innovation rate $t$ increases. In the model with Southern-resource-using RPAs, however, the rise in $w_{L N}$ works to strengthen the negative innovation incentives. In addition, there is now a direct effect of a higher $\eta_{S}$ that works through $c_{N}$. The mechanism is as follows. An increase in $\eta_{S}$ raises imitation costs by increasing the intensity of imitation-deterring activities. The resulting decline in imitation profitability induces resources to move from imitation to Southern manufacturing. Through the BOT condition, this translates into increased expenditure in Northern products and thus an expansion in Northern manufacturing. Consequently, with both Northern and the Southern manufacturing expanding (i.e., $c_{N}$ and $c_{S}$ increasing), the profit flows enjoyed by Northern innovators increase. This direct effect is absent in the baseline model and can work to overturn the negative innovation incentives. Hence, the innovation rate $l$ can go either way. Observe that in the comparison of the two models, the differential response of the North-South general-purpose wage rate $w_{L N}$ and the direct impact of $\eta_{S}$ on Northern per-capita expenditure $c_{N}$ play crucial roles in determining the net change in innovation incentives and thus the change in $l$.

\subsection{Trade liberalization with a low-tech sector in the South}

We now introduce inter-industry trade to our basic setup and reevaluate the tariff-neutrality result of Proposition 2 . We assume that in the South, there is an additional, perfectly competitive sector which produces a low-tech good $Z$ according to the production function $Z_{S}=b L_{Z}$, where $b>0$ is a productivity factor and $L_{Z}$ is Southern labor input in $Z$ production. The two distinctive features relative to the other ("high-tech") sector are that, first, no innovation targets the low-tech sector, and, second, the South is the sole producer of the low-tech good and thus becomes the net exporter of this product to the North. ${ }^{28}$ The real wage received by Southern low-tech workers equals their marginal product $b$, hence $w_{Z}=b p_{Z}$, with $p_{Z}$ being the supply price for $Z$. Since Southern workers are perfectly mobile between the high-tech and the low-tech sector, and the wage rate in the former is normalized to 1 , the low-tech goods price is fixed to the unit labor requirement, $p_{Z}=1 / b$. This is also the price faced by Northern consumers, given that we assume free trade for low-tech goods (which is reasonable since there is no low-tech Northern industry to protect).

The reduced form of the instantaneous utility function (2) changes to

$$
\log u_{i}(t) \equiv \alpha \int_{0}^{1} \log \left[\frac{\lambda^{j(\omega, t)} c_{i}(t)}{p(\omega, t)}\right] d \omega+(1-\alpha) \log \left[\frac{z_{i}(t)}{p_{Z}}\right],
$$

where $\alpha \in(0,1)$ is a taste parameter and $z_{i}(t)$ denotes the per-capita consumption expenditure for the low-tech goods at time $t$ in country $i$. The household's optimization problem is to maximize discounted utility (1) with the subutility function (37) subject to the intertemporal budget constraint

$$
W I_{i}(t)+F A_{i}(t)=\int_{t}^{\infty} e^{-[R(s)-R(t)]}\left[c_{i}(s)+z(s)\right] d s .
$$

In (38), $W I_{i}$ denotes the discounted wage income per capita of the representative household in country $i$ from time $t$ on, $F A_{i}(t)$ is the value of the financial assets per capita of the representative household in country $i$ at time $t$, and $R(t) \equiv \int_{0}^{t} r(s) d s$ is the market discount factor with $\dot{R}(t)=r(t)$ denoting the instantaneous interest rate at time $t$. Appendix $\mathrm{C}$ derives the following additional condition for optimal consumer behavior in both countries:

$$
c_{i} / z_{i}=\alpha /(1-\alpha) \text { for } i=N, S,
$$

hence in each country, consumers spend a portion $\alpha$ on high-tech goods and the rest $(1-\alpha)$ of their expenditure on lowtech goods.

The free-entry conditions (25) and (26) remain unchanged because the functions for Northern and Southern monopoly profits, (5) and (6), do not change, respectively. The Northern general-purpose labor market clearing condition (30) also does not change since (18) is not affected, but the Southern labor market clearing condition (31) changes because we have to account for Southern labor demand in the low-tech sector $L_{Z}$. This is derived by imposing that the value of Northern lowtech consumption must equal the value of Southern low-tech exports:

$$
\begin{aligned}
& z_{N} N_{N}=\frac{1-\alpha}{\alpha} c_{N} N_{N} \stackrel{!}{=} p_{Z} Z_{S}-z_{S} N_{S}=L_{Z}-\frac{1-\alpha}{\alpha} c_{S} N_{S}, \\
& \Leftrightarrow L_{Z}=\frac{1-\alpha}{\alpha}\left(c_{N} N_{N}+c_{S} N_{S}\right),
\end{aligned}
$$

where we have used (39), $Z_{S}=b L_{Z}$, and $p_{Z}=1 / b$. The BOT condition now implies that the value of Northern exports of high-tech goods net of tariffs must equal the value of Southern high-tech exports net of tariffs plus the value of Southern

\footnotetext{
${ }^{28}$ The modeling of the low-tech sector follows Grieben $(2004,2005)$.
} 
low-tech exports, formally:

$$
\begin{aligned}
& n_{N} \frac{c_{S} N_{S}}{\lambda} \frac{\lambda}{\left(1+\tau_{S}\right)}=n_{S} \frac{c_{N} N_{N}}{w_{L N}} \frac{w_{L N}}{\left(1+\tau_{N}\right)}+\frac{(1-\alpha) c_{N} N_{N}}{\alpha}, \\
& \Leftrightarrow \frac{c_{S}}{c_{N}}=\frac{1+\tau_{S}}{n_{N} \eta_{S}}\left(\frac{n_{S}}{1+\tau_{N}}+\frac{1-\alpha}{\alpha}\right)=\frac{1+\tau_{S}}{l \eta_{S}}\left[\frac{\mu}{1+\tau_{N}}+\frac{(l+\mu)(1-\alpha)}{\alpha}\right] \quad \operatorname{BOT}\left(c_{N}, c_{S}, l, \mu\right),
\end{aligned}
$$

where (21) is used for the last equality. With (40) included and using (21), (20) is replaced by

$$
\frac{Q_{S}\left(c_{N}, c_{S}\right) \mu}{\eta_{S}(l+\mu)}+\frac{A_{\mu} \mu s_{N}}{\eta_{S}} \frac{l}{(l+\mu)}+\frac{1-\alpha}{\alpha}\left(\frac{c_{N}}{\eta_{S}}+c_{S}\right)=1 \quad \operatorname{LABS}\left(c_{N}, c_{S}, l, \mu\right)
$$

Setting (24) equal to (13), substituting for $D$ from (10), then for $X n_{N}$ from (19), and imposing the new BOT condition (41), we obtain the new $\operatorname{FEIN}\left(c_{N}, w_{L N}, l, \mu\right)$ condition as

$$
c_{N} \frac{l\left\{\left[\lambda\left(1+\tau_{N}\right) / \alpha\right]-w_{L N}\left[1+\left(1+\tau_{N}\right)\left(1+\tau_{S}\right)(1-\alpha) / \alpha\right]\right\}+\mu\left\{\left[1+\tau_{N}(1-\alpha)\right] / \alpha\right\}\left[\lambda-\left(1+\tau_{S}\right) w_{L N}\right]}{l \lambda\left(1+\tau_{N}\right)[\rho-n+2(l+\mu)]}=A_{l} w_{L N} S_{N} .
$$

Analogously, by setting (14) equal to (16), and using (6), (10), (19), and (41), we obtain the new $\operatorname{FEIM}\left(c_{N}, w_{L N}, l, \mu\right)$ condition as

$$
c_{N} \frac{l\left\{-\left[\left(1+\tau_{N}\right) / \alpha\right]+w_{L N}\left[1+\left(1+\tau_{N}\right)\left(1+\tau_{S}\right)(1-\alpha) / \alpha\right]\right\}+\mu\left\{\left[1+\tau_{N}(1-\alpha)\right] / \alpha\right\}\left[w_{L N}\left(1+\tau_{S}\right)-1\right]}{l w_{L N}\left(1+\tau_{N}\right)(\rho-n+l)}=A_{\mu} s_{N} .
$$

The curve for (43) is unambiguously upward sloping and the curve for (44) is unambiguously downward sloping in $\left(c_{N}, w_{L N}\right)$ space as in Fig. 2. Solving (43) and (44) simultaneously for $c_{N}$ and $w_{L N}$ yields $c_{N}(l, \mu)$ and $w_{L N}(l, \mu)$, given in Appendix C. Using (41) and $c_{N}(l, \mu)$ in (30) gives again (32) as the upward-sloping $\operatorname{LABN}(\iota, \mu)$ condition since without lowtech production in the North, all terms containing $\alpha$ and the tariff rates just cancel out. Substituting $c_{N}(1, \mu)$ in $(42)$ and using (41) gives a new expression for $\operatorname{LABS}(1, \mu)$ as stated in Appendix D, Eq. (D.1), which is downward sloping for sufficiently low tariff rates.

We now discuss the mechanisms by which trade liberalization affects the global economy. ${ }^{29}$ As in our baseline model without a Southern low-tech sector, a decline in the Northern tariff rate $\tau_{N}$ reduces the level of $c_{N}$ for given $t$ and $\mu$. The mechanisms remain the same. A lower $\tau_{N}$ exerts two competing effects on Northern firms' profits: a negative through reduced protection in their domestic market, and a positive through a Southern TOT improvement, which tends to increase $c_{S}$. With two competing effects on innovation profitability, the FEIN curve in Fig. 2 may shift in either direction. In addition, a lower $\tau_{N}$ raises Southern firms' profits $\pi_{S}$ by increasing $w_{L N} /\left(1+\tau_{N}\right)$ and $c_{S}$. To restore the FEIM condition (44), $c_{N}$ must decline and hence the FEIM curve shifts down in Fig. 2. The net effect of both curves' shifts implies again a lower $c_{N}$, see Eq. (C.7).

What is different in the model with the Southern low-tech sector is that the decline in $\tau_{N}$ now also reduces $c_{S}$, which was unaffected in the baseline model. To see the mechanism, focus on the first line of the BOT condition in (41). The lower $\tau_{N}$ directly increases $c_{S}$ via the Southern TOT improvement and indirectly decreases $c_{S}$ via the fall in $c_{N}$. The TOT-driven increase in $c_{S}$ is independent of $\alpha$ and hence is as strong as in the baseline model, where $\alpha=1$. Meanwhile the $c_{N}$-triggered decrease in $c_{S}$ becomes larger in the model with a Southern low-tech sector, where $\alpha<1$. The intuitive reasoning is that with $\alpha<1$, the lower $c_{N}$ not only reduces the net-of-tariff value of Southern high-tech exports $n_{S} c_{N} N_{N} /\left(1+\tau_{N}\right)$ but also the value of Southern low-tech exports $(1-\alpha) c_{N} N_{N} / \alpha$ because the consumer optimality condition (39) dictates a constant high-tech to low-tech spending ratio. Hence, $c_{S}$ decreases due to two forces. We show formally in $(C .8)$ that for $\alpha<1$, the $c_{N}$-triggered decrease in $c_{S}$ dominates the TOT-driven increase in $c_{S}$, and thus $c_{S}$ declines.

With both $c_{N}$ and $c_{S}$ declining, the Southern low-tech sector unambiguously contracts, see the third term on the RHS of (42), and also (40). In addition, using (41), (C.5) and (C.6) reveals that Southern high-tech production per industry $Q_{S} N_{N}$ again is independent of tariffs, as in the baseline model. Thus, the decline in low-tech production creates room for an expansion in imitation activity, implying an increase in $\mu$ to clear the Southern labor market. Consequently, for a given $t$, the LABS curve shifts to the right as in Fig. 4. Since the LABN curve does not shift, the equilibrium levels of $\iota$ and $\mu$ both increase. Intuitively, the increase in $\imath$ follows from the upward sloping LABN curve: the decline in Northern labor demand triggered by a higher $\mu$ (which reduces Northern production labor demand by reducing the share of Northern industries $n_{N}$ and also Northern consumption expenditure $c_{N}$ ) must be offset by a higher $l$, which raises Northern employment in both production and R\&D again.

We now investigate the impact of a decline in $\tau_{S}$. It exerts two competing effects on $\pi_{N}^{P}$. First, a lower $\tau_{S}$ increases $\pi_{N}^{P}$ by increasing the Northern net-of-tariff export revenue per unit, $\lambda /\left(1+\tau_{S}\right)$. Second, a lower $\tau_{S}$ decreases $\pi_{N}^{P}$ by decreasing $c_{S}$ through the BOT condition (41), which is triggered by the increase in the Northern net-of-tariff export price $\lambda /\left(1+\tau_{S}\right)$, a TOT

\footnotetext{
${ }^{29}$ Formal derivations for tariff results can be found in Appendix C. We should note that an increase in $\eta_{S}$ generates the same effects as in the baseline model. It implies a rightward shift of the LABS curve, leading to higher levels of $\iota$ and $\mu$. The steady-state North-South relative wage $w_{L N}$ declines via the same mechanisms discussed in the baseline model.
} 
deterioration for the South. The net effect turns out to be an increase in the Northern firms' profit flow. To restore equilibrium, $c_{N}$ must decrease and the FEIN curve shifts down.

Next, a lower $\tau_{S}$ decreases Southern firms' profits $\pi_{S}$ by reducing protection for Southern incumbents in the domestic market, which forces them to cut their limit price $p_{S}^{S}$. This effect is magnified by the fall in $c_{S}$ driven by the Southern TOT deterioration. To restore the FEIM condition (44), $c_{N}$ must increase, and the FEIM curve shifts up. The net effect of both curves' shifts in Fig. 2 turns out to be that a lower $\tau_{S}$ increases $c_{N}$. To determine the change in $c_{S}$, we note from the BOT condition (41) that $c_{S}$ increases with $c_{N}$ and decreases with the Southern TOT deterioration. The net effect is a decrease in $c_{S}{ }^{30}$

With $c_{N}$ increasing and $c_{S}$ decreasing, the net impact on the Southern low-tech sector appears ambiguous, but the $c_{N}$ effect turns out to dominate (as long as $\tau_{N}>0$, see (C.11)) and thus Southern low-tech sector employment $L_{Z}$ increases. Since Southern high-tech production per industry $Q_{S} N_{N}$ is independent of $\tau_{S}$, the expansion in the Southern low-tech sector leaves less resources for imitation, implying a decrease in $\mu$ to clear the Southern labor market. Consequently, for a given $l$, the LABS curve shifts to the left, opposite to the situation shown in Fig. 4. The equilibrium levels of both $t$ and $\mu$ decline. We summarize our findings in

Proposition 3. In the neighborhood of sufficiently low but positive tariffs, a unilateral reduction of the Southern (Northern) import tariff $\tau_{S}\left(\tau_{N}\right)$ results in a decrease (an increase) in the industry-wide rates of both Northern innovation and Southern imitation.

The formal proof of Proposition 3, including the existence and uniqueness of equilibrium, is provided in Appendix D. We have also analyzed the effects of bilateral trade liberalization with $\Delta \tau_{N}=\Delta \tau_{S}<0$ (which allows for different starting levels of tariff rates). The result is qualitatively equivalent to unilateral Northern trade liberalization, but the positive growth effect is obviously smaller since Southern trade liberalization works towards reducing innovation and growth (for details see Appendix E). These findings imply:

\section{Main Result 2}

If a Southern low-tech sector is added to the baseline model of Section 2, in the neighborhood of sufficiently low but positive tariffs

i. Northern (Southern) unilateral trade liberalization unambiguously raises (reduces) growth in both countries; hence, the tariffneutrality result of Proposition 2 no longer holds,

ii. bilateral trade liberalization has qualitatively the same but quantitatively a weaker implication for growth compared to unilateral Northern trade liberalization; this provides the North with an argument for 'going alone' in freeing trade.

Observe that in the model with the Southern low-tech sector, the additional export value due to Southern low-tech exports entering the new BOT condition (41) coupled with the required proportionality of high-tech and low-tech consumption expenditure from consumer optimization (39) play crucial roles in overturning the tariff-neutrality result of Proposition $2 .^{31}$

\section{Conclusions}

We analyze the long-run economic growth effects of globalization in a fully endogenous growth model that features rent-protection activities and is free of scale effects. We consider two aspects of globalization: increased North-South trade integration and incremental trade liberalization.

\footnotetext{
${ }^{30}$ It should be noted that the positive response of $c_{S}$ triggered by the increase in $c_{N}$ is stronger when a Southern low-tech sector exists (i.e., the case with $\alpha<1$ ). It follows from the BOT condition (41) that the $c_{N}$ increase boosts the value of both Southern high-tech exports and low-tech exports for given $n_{S}$. Thus, in comparison to the baseline model of Section 3.2, there is an additional increase in Southern exports due to the increase in low-tech exports, which ceteris paribus generates a further increase in $c_{S}$. This attenuates but not completely offsets the initial negative TOT effect on $c_{S}$.

31 The Appendices R.5-R.8 (available upon request) show that our central findings are to a large extent robust to two alternative labor assignments. In the first alternative, we consider only one type of labor that can perform all three types of activities (production, R\&D and RPAs). This model yields less than fully endogenous growth in the sense that the rate of innovation $t$ is pinned down by a small subset of parameters, excluding tariff rates and $\eta_{S}$. Propositions 1 and 2 continue to hold with the only exception that in Proposition 2 an increase in $\eta_{s}$ now exerts no effect on $l$. Thus, the innovation effects stated in part ii. of Main Result 1 and Proposition 3 are effectively muted. However, part i. of Main Result 1 remains fully intact. In the second alternative, we consider two types of labor as in the baseline model. We assume that Northern general-purpose labor is mobile between R\&D, manufacturing and also RPAs, while specialized labor performs only RPAs as before. This model resurrects fully endogenous growth, in the sense that $\iota$ responds to most of the model's parameters, excluding tariff rates but including $\eta_{s}$, as in the baseline model. Propositions 1 and 2 continue to hold. Main Result 1 part ii. still continues to hold, whereas part i. can no longer be checked analytically. With RPA using two types of labor and the South having a low-tech sector the model becomes too complex to analytically check the robustness of Proposition 3 . We conjecture though that in this case there will at least be a range for the share of specialized labor in unit-production costs of RPA $\beta \in\left(\beta^{\min }, 1\right)$ in which the results from the baseline model will hold, where $\beta=1$ is the case considered in the main text. See Sener (2008, pp. 3912-3913) for further discussion of such robustness checks in a similar but closed economy setting.
} 
Our model provides a unique setting that highlights the economic consequences of increased trade integration of the South under different institutional set-ups for RPAs. We find that when imitation-deterring activities use Northern resources (e.g., US firms hire US lawyers to lobby the US government for more strict IPR protection), increased North-South integration unambiguously increases Northern innovation and thus worldwide growth. However, when imitation-deterring activities use Southern resources (e.g., US firms hire Chinese lawyers for patent litigation cases in China), the positive growth effect can be reversed. Our results also highlight the need for more systematic data collection on the location of these RPAs, which may pave the way for more empirical research on this issue.

We also show that the sectoral production and trade structures are important in determining the economic effects of incremental tariff reductions. We show that when the production and trade structures are symmetric between the countries (one-sector economy in both countries), tariffs do not matter for long-run growth at all. This finding is shown to be robust to various alternative specifications concerning other aspects of the model. Since many low-tech industries are vanishing in high-wage Northern countries, an asymmetric production and trade structure with a low-tech industry located only in the developing South appears to be the more empirically relevant case. We show that in this case, Northern (Southern) unilateral trade liberalization is conducive (detrimental) for Northern innovation and worldwide long-run growth.

From a theoretical perspective, we clarify for the first time the precise channels by which unilateral Northern and Southern trade liberalization affect long-run growth in a Schumpeterian model without scale effects. From a policy perspective, two strong recommendations follow: first, the South's refusal to reduce its trade barriers should not be an excuse for the North to refrain from trade liberalization as well (contrary to what is regularly observed at WTO negotiations). Second, by imposing import tariffs on Southern imitated goods, the North can reduce the threat of Southern imitation, but in general equilibrium, this hurts the North by leading to lower rates of innovation and growth.

\section{Acknowledgements}

Part of this work was done while Wolf-Heimo Grieben was a visiting scholar at the economics department of Columbia University, New York. We thank them for their hospitality. This work was supported by a grant from the Ministry of Science, Research and the Arts of Baden-Württemberg, Germany (Az: 21-655.042-5-2/1) to Wolf-Heimo Grieben. We thank two referees for their very helpful and constructive comments. The usual disclaimer applies.

\section{Appendices}

Appendix A. Proof of Proposition $1^{32}$

Applying Cramer's rule for the system of two Eqs. (32) and (33), we obtain

$$
\left(\begin{array}{l}
\frac{\partial t}{\partial \eta_{S}} \\
\frac{\partial \mu}{\partial \eta_{S}}
\end{array}\right)=\left(\begin{array}{l}
\frac{\left[A_{t}(\rho-n)+A_{\mu}(\rho-n+l)\right] K_{1}}{\eta_{S}\left(K_{2}+K_{3}+K_{4}\right)}>0 \\
\frac{\left\{A_{\mu}\left[1^{2}+(\rho-n) \mu+2 \imath \mu\right]+A_{1}\left[(\rho-n) \mu+(1+\lambda)(t+\mu)^{2}\right]\right\} K_{1}}{\eta_{S}\left(K_{2}+K_{3}+K_{4}\right)}>0
\end{array}\right)
$$

where

$$
\begin{aligned}
& K_{1} \equiv \mu\left\{A_{\mu}(\rho-n+\imath \lambda)+A_{l} \lambda[\rho-n+2(l+\mu)]\right\}>0, \\
& K_{2} \equiv A_{l} A_{\mu}(l+\mu)\{l[\rho-n+2 \lambda(\rho-n)+\imath \lambda(3+\lambda)]+2(\rho-n+2 \imath) \lambda \mu\}>0, \\
& K_{3} \equiv A_{l}^{2} \lambda(l+\mu)\left[2(1+\lambda)(l+\mu)^{2}+(\rho-n)(l+\imath \lambda+2 \mu)\right]>0, \\
& K_{4} \equiv A_{\mu}^{2} \imath[\imath \lambda(l+\mu)+(\rho-n)(l+\lambda \mu)]>0 .
\end{aligned}
$$

From $m \equiv \mu n_{N}=\mu \imath /(l+\mu)$, it follows $\partial m / \partial \eta_{S}=[\mu /(\imath+\mu)]^{2} \partial \imath / \partial \eta_{S}+[\imath /(l+\mu)]^{2} \partial \mu / \partial \eta_{S}>0$. From $n_{N}=\imath /(l+\mu)$, it follows $\partial n_{N} / \partial \eta_{S}=$ $[1 /(l+\mu)]^{2}\left[\mu\left(\partial \iota / \partial \eta_{S}\right)-l\left(\partial \mu / \partial \eta_{S}\right)\right]$, which gives

$$
\frac{\partial n_{N}}{\partial \eta_{S}}=-\frac{l\left[A_{\mu} l+A_{l}(1+\lambda)(l+\mu)\right] K_{1}}{\eta_{S}(l+\mu)\left(K_{2}+K_{3}+K_{4}\right)}<0
$$

Finally, evaluating (28) for $\tau_{N}=\tau_{S}=0$, differentiating with respect to $\eta_{S}$ and using (A.1) gives

$$
\left.\frac{\partial w_{L N}}{\partial \eta_{S}}\right|_{\tau_{N}=\tau_{S}=0}=-\frac{A_{l} A_{\mu}(\lambda-1) \lambda K_{1}\left(K_{5}+K_{6}+K_{7}\right)}{\eta_{S}\left\{A_{\mu}(\rho-n+l)+A_{l} \lambda[\rho-n+2(l+\mu)]\right\}^{2}\left(K_{2}+K_{3}+K_{4}\right)}<0
$$

\footnotetext{
${ }^{32}$ Here we provide the main results of a corresponding Mathematica ${ }^{\oplus}$ program, which is available from the authors upon request.
} 
where

$$
\begin{aligned}
& K_{5}=\imath(\rho-n)\left[(\rho-n)\left(A_{l}+A_{\mu}\right)+\imath A_{\mu}\right]>0, \\
& K_{6}=2(\rho-n)\left\{(\rho-n) A_{l} \mu+A_{\mu}\left[l^{2}+\mu(\rho-n+2 l)\right]\right\}>0, \\
& K_{7}=2(l+\mu)\left[A_{l}(1+\lambda)(l+\mu)(\rho-n+l)+A_{\mu} l^{2}\right]>0 .
\end{aligned}
$$

\section{Appendix B. Technical details for Section 4.1}

The FEIN and FEIM equations are:

$$
\begin{aligned}
& \frac{c_{N}(l+\mu)\left(\lambda-w_{L N}\right)}{l \lambda[\rho-n+2(l+\mu)]}=\hat{A}_{1} w_{L N} s_{N} \quad \operatorname{FEIN}\left(c_{N}, w_{L N}, l, \mu\right), \\
& \frac{c_{N}(l+\mu)\left(w_{L N}-1\right)}{l w_{L N}(\rho-n+l)}=\hat{A}_{\mu} s_{S} \eta_{S} \quad \operatorname{FEIM}\left(c_{N}, w_{L N}, l, \mu\right) .
\end{aligned}
$$

Taking the ratio of (B.1) and (B.2) gives the relative profitability condition

$$
\frac{\lambda-w_{L N}}{\lambda\left(w_{L N}-1\right)} \cdot \frac{\rho-n+l}{\rho-n+2(l+\mu)}=\frac{\hat{A}_{l} s_{N}}{\hat{A}_{\mu} s_{S} \eta_{S}} .
$$

Solving (B.1) and (B.2) simultaneously for $w_{L N}$ and $c_{N}$ gives

$$
\begin{aligned}
& w_{L N}=\frac{\lambda\left\{\hat{A}_{l} s_{N}[\rho-n+2(l+\mu)]+\hat{A}_{\mu} s_{S} \eta_{S}(\rho-n+l)\right\}}{\lambda \hat{A}_{l} s_{N}[\rho-n+2(l+\mu)]+\hat{A}_{\mu} s_{S} \eta_{S}(\rho-n+l)}, \\
& c_{N}=\frac{\imath \lambda\left\{\hat{A}_{l} s_{N}[\rho-n+2(l+\mu)]+\hat{A}_{\mu} s_{S} \eta_{S}(\rho-n+l)\right\}}{(\lambda-1)(l+\mu)} .
\end{aligned}
$$

The ratio $c_{N} / w_{L N}$ is then found as

$$
\frac{c_{N}}{w_{L N}}=\frac{l\left\{\lambda \hat{A}_{l} s_{N}[\rho-n+2(l+\mu)]+\hat{A}_{\mu} s_{S} \eta_{S}(\rho-n+l)\right\}}{(\lambda-1)(l+\mu)},
$$

which is unambiguously increasing in $\eta_{s}$. Substituting (B.5) in (35), LABN becomes

$$
\frac{l\left\{\hat{A}_{l} s_{N}[\rho-n+(l+\mu)(1+\lambda)]+\hat{A}_{\mu} s_{s} \eta_{S}(\rho-n+l)\right\}}{(\lambda-1)(l+\mu)}=1-s_{N} \quad \operatorname{LABN}(l, \mu),
$$

which is unambiguously upward sloping in $(l, \mu)$ space as before. Substituting (B.6) in (36), LABS becomes

$$
\frac{\mu\left\{\lambda \hat{A}_{l} s_{N}[\rho-n+2(l+\mu)]+\hat{A}_{\mu} s_{S} \eta_{S}(\rho-n+l \lambda)\right\}}{\eta_{S}(\lambda-1)(l+\mu)}=1-s_{S} \quad \operatorname{LABS}(l, \mu) .
$$

The LHS of (B.8) is unambiguously increasing in $\mu$, and it is increasing in $\imath$ if, and only if,

$$
\mu>(\rho-n)\left(\frac{1}{\lambda}+\frac{\hat{A}_{l} s_{N}}{\hat{A}_{\mu} s_{S} \eta_{S}}\right)
$$

is fulfilled, which corresponds to (34). Given this, the curve for the LABS Eq. (B.8) is downward sloping in $(l, \mu)$ space as before.

To sign $\partial \imath / \partial \eta_{S}$ and $\partial w_{L N} / \partial \eta_{S},{ }^{33}$ we apply Cramer's rule to the system of two Eqs. (B.7) and (B.8):

$$
\left(\begin{array}{c}
\frac{\partial l}{\partial \eta_{S}} \\
\frac{\partial \mu}{\partial \eta_{S}}
\end{array}\right)=\left(\begin{array}{c}
-\frac{l\left(K_{8}+K_{g}\right)}{\eta_{S}\left(s_{N} s_{S} \eta_{S} K_{2}+s_{N}^{2} K_{3}+s_{S}^{2} \eta_{S}^{2} K_{4}\right)} \\
\frac{\mu\left(K_{10}-K_{11}+K_{12}\right)}{\eta_{S}\left(s_{N} s_{S} \eta_{S} K_{2}+s_{N}^{2} K_{3}+s_{S}^{2} \eta_{S}^{2} K_{4}\right)}
\end{array}\right)
$$

where

$$
K_{8} \equiv s_{S}^{2} \eta_{S}^{2} A_{\mu}^{2} l(\rho-n+\imath)(\rho-n+\imath \lambda)-s_{N}^{2} \mu A_{\imath}^{2} \lambda(\rho-n)[\rho-n+2(l+\mu)] \lessgtr 0,
$$

\footnotetext{
${ }^{33}$ We provide the main results of a corresponding Mathematica ${ }^{\star}$ program which is available upon request.
} 


$$
\begin{aligned}
& K_{9} \equiv s_{N} S_{S} \eta_{S} A_{l} A_{\mu} \lambda(\rho-n+l)[(\rho-n)(l-\mu)+2 l(l+\mu)] \lessgtr 0, \\
& K_{10} \equiv A_{t}^{2} s_{N}^{2} \lambda[\rho-n+2(l+\mu)]\left[(\rho-n) \mu+(1+\lambda)(l+\mu)^{2}\right]>0, \\
& K_{11} \equiv A_{\mu}^{2} l(\rho-n+l) s_{S}^{2} \eta_{S}^{2}(\rho-n-\mu \lambda) \lessgtr 0, \\
& K_{12} \equiv s_{N} S_{S} \eta_{S} A_{l} A_{\mu} \lambda\left[(\rho-n)^{2}(\mu-l)+2(\rho-n) \mu(2 l+\mu)+2 l(l+\mu)(l+2 \mu)\right] \lessgtr 0 .
\end{aligned}
$$

From the first line of (B.10) and the definitions of $K_{8}$ and $K_{9}$ it immediately follows that $\partial \imath / \partial \eta_{S}<0$ for a sufficiently small discount rate $\rho-n$.

Differentiating (B.4) with respect to $\eta_{S}$ and using (B.10) gives

$$
\frac{\partial w_{L N}}{\partial \eta_{S}}=\frac{s_{N} s_{S}(\lambda-1) \lambda A_{\imath} A_{\mu} l\left(s_{N}^{2} A_{t}^{2} \lambda K_{13}+s_{S}^{2} \eta_{S}^{2} A_{\mu}^{2} K_{14}+s_{N} s_{S} \eta_{S} A_{l} A_{\mu} K_{15}\right)}{\left\{s_{N} A_{l} \lambda[\rho-n+2(l+\mu)]+s_{S} \eta_{S} A_{\mu}(\rho-n+l)\right\}^{2} K_{16}}>0
$$

where

$$
\begin{aligned}
& K_{13} \equiv\{l(\rho-n+l)(1+\lambda)+[2(\rho-n)+\imath+(\rho-n+l) \lambda] \mu\}[\rho-n+2(l+\mu)]^{2}>0, \\
& K_{14} \equiv(\rho-n+\imath)^{2}[2(\rho-n) l+(\rho-n)(2+\lambda) \mu+2 \imath \lambda(l+\mu)]>0, \\
& K_{15} \equiv(\rho-n+\imath)[\rho-n+2(l+\mu)][l \lambda(3+\lambda)(l+\mu)+(\rho-n)(l+3 \imath \lambda+\mu+5 \lambda \mu)]>0, \\
& K_{16} \equiv s_{N} s_{S} \eta_{S} K_{2}+s_{N}^{2} K_{3}+s_{S}^{2} \eta_{S}^{2} K_{4}>0 .
\end{aligned}
$$

Appendix C. Technical details of Section 4.2

To solve the household's optimization problem of maximizing (1) subject to (37) and (38), we define a new state variable $\Theta$ with

$$
\dot{\Theta}(s)=e^{-[R(s)-R(t)]}\left[c_{i}(s)+z_{i}(s)\right], \quad \Theta(0)=0, \quad \text { and } \quad \lim _{s \rightarrow \infty} \Theta(s)=W I_{i}(t)+F A_{i}(t) .
$$

With $p_{Z}=1 / b$, the present-value Hamilton function can be written as

$$
H\left(\Theta, c_{i}, z_{i}, \chi, t\right)=e^{-\rho s}\left\{\alpha \log \left[c_{i}(s)\right]+(1-\alpha) \log \left[b z_{i}(s)\right]\right\}+\chi(s) e^{-[R(s)-R(t)]}\left[c_{i}(s)+z_{i}(s)\right]
$$

with $\chi(s)$ as the new costate variable corresponding to $\Theta(s)$. The costate equation $\partial H / \partial \Theta=0=-\dot{\chi}$ implies $\chi(s)=\chi \forall s$. Applying Pontryagin's maximum principle yields the other foc:

$$
\begin{aligned}
& \partial H / \partial c_{i}(s)=e^{-\rho s}\left[\alpha / c_{i}(s)\right]+\chi e^{-[R(s)-R(t)]} \stackrel{!}{=} 0, \\
& \partial H / \partial z_{i}(s)=e^{-\rho s}\left[(1-\alpha) / z_{i}(s)\right]+\chi e^{-[R(s)-R(t)]} \stackrel{!}{=} 0 .
\end{aligned}
$$

Differentiating (C.3) with respect to time $s$, and applying $\dot{R}(s) \equiv r(s)$ and (C.3) yield the optimal consumption path for lowtech goods

$$
\dot{z}_{i}(t) / z_{i}(t)=r(t)-\rho \quad \text { with } i=N, S .
$$

Dividing (C.2) by (C.3) yields Eq. (39) of the main text.

Solving the new FEIN Eq. (43) and the new FEIM Eq. (44) simultaneously for $c_{N}$ and $w_{L N}$ yields:

$$
\begin{aligned}
& c_{N}(l, \mu)=\frac{l S_{N} \lambda\left(1+\tau_{N}\right)\left\{A_{l}[\rho-n+2(l+\mu)]+A_{\mu}(\rho-n+l)\right\}}{(\lambda-1)\left\{l\left[1+\frac{1-\alpha}{\alpha}\left(1+\tau_{N}\right)\left(1+\tau_{S}\right)\right]+\frac{\mu}{\alpha}\left[1+\tau_{N}(1-\alpha)\right]\left(1+\tau_{S}\right)\right\}}, \\
& w_{L N}(l, \mu)=\frac{\lambda\left\{A_{l}[\rho-n+2(l+\mu)]+A_{\mu}(\rho-n+l)\right\}\left\{\frac{l}{\alpha}\left(1+\tau_{N}\right)+\frac{\mu}{\alpha}\left[1+\tau_{N}(1-\alpha)\right]\right\}}{\left\{A_{l} \lambda[\rho-n+2(l+\mu)]+A_{\mu}(\rho-n+l)\right\}\left\{l\left[1+\frac{1-\alpha}{\alpha}\left(1+\tau_{N}\right)\left(1+\tau_{S}\right)\right]+\frac{\mu}{\alpha}\left[1+\tau_{N}(1-\alpha)\right]\left(1+\tau_{S}\right)\right\}},
\end{aligned}
$$

where setting $\alpha=1$ in (C.5) and (C.6) yields the baseline model's solutions (27) and (28), respectively. $c_{N}(l, \mu)$ is unambiguously increasing in $\tau_{\mathrm{N}}$ :

$$
\frac{\partial c_{N}}{\partial \tau_{N}}=\frac{l s_{N} \lambda\left\{A_{\mu}[\rho-n+l]+A_{l}[\rho-n+2(l+\mu)]\right\}\left[l+\mu\left(1+\tau_{S}\right)\right]}{(\lambda-1)\left\{(l+\mu) \frac{1}{\alpha}\left[1+(1-\alpha) \tau_{N}\right]+\tau_{S}\left[\mu+((1-\alpha) / \alpha)(l+\mu)\left(1+\tau_{N}\right)\right]\right\}^{2}}>0 .
$$


Using (C.5) and (41) shows that $c_{S}(l, \mu)$ is also unambiguously increasing in $\tau_{N}$ :

$$
\frac{\partial c_{S}}{\partial \tau_{N}}=\frac{((1-\alpha) / \alpha) l s_{N} \lambda(l+\mu)\left(l+\tau_{S}\right)\left\{A_{\mu}[\rho-n+l]+A_{l}[\rho-n+2(l+\mu)]\right\}}{\eta_{S}(\lambda-1)\left\{(l+\mu) \frac{1}{\alpha}\left[1+(1-\alpha) \tau_{N}\right]+\tau_{S}\left[\mu+((1-\alpha) / \alpha)(l+\mu)\left(1+\tau_{N}\right)\right]\right\}^{2}}>0 .
$$

$c_{N}(l, \mu)$ is unambiguously decreasing in $\tau_{S}$ :

$$
\frac{\partial c_{N}}{\partial \tau_{S}}=-\frac{l S_{N} \lambda\left\{A_{\mu}(\rho-n+l)+A_{l}[\rho-n+2(l+\mu)]\right\}\left(1+\tau_{N}\right)\left[\mu+((1-\alpha) / \alpha)(l+\mu)\left(1+\tau_{N}\right)\right]}{(\lambda-1)\left\{(l+\mu)(1 / \alpha)\left[1+(1-\alpha) \tau_{N}\right]+\tau_{S}\left[\mu+((1-\alpha) / \alpha)(l+\mu)\left(1+\tau_{N}\right)\right]\right\}^{2}}<0 .
$$

$c_{S}(l, \mu)$ is unambiguously increasing in $\tau_{S}$ :

$$
\frac{\partial c_{S}}{\partial \tau_{S}}=\frac{l S_{N} \lambda\left\{A_{\mu}(\rho-n+l)+A_{l}[\rho-n+2(l+\mu)]\right\}\left(1+\tau_{N}\right)\left[\mu+((1-\alpha) / \alpha)(l+\mu)\left(1+\tau_{N}\right)\right]}{\eta_{S}(\lambda-1)\left\{(l+\mu)(1 / \alpha)\left[1+(1-\alpha) \tau_{N}\right]+\tau_{S}\left[\mu+((1-\alpha) / \alpha)(l+\mu)\left(1+\tau_{N}\right)\right]\right\}^{2}}>0 .
$$

To determine the sign of $\partial L_{Z} / \partial \tau_{S}$, we evaluate the following expression:

$$
\frac{\partial\left[\left(c_{N} / \eta_{S}\right)+c_{S}\right]}{\partial \tau_{S}}=-\frac{l s_{N} \lambda\left\{A_{\mu}(\rho-n+l)+A_{l}[\rho-n+2(l+\mu)]\right\} \tau_{N}\left[\mu+((1-\alpha) / \alpha)(l+\mu)\left(1+\tau_{N}\right)\right]}{\eta_{S}(\lambda-1)\left\{(l+\mu)(1 / \alpha)\left[1+(1-\alpha) \tau_{N}\right]+\tau_{S}\left[\mu+((1-\alpha) / \alpha)(l+\mu)\left(1+\tau_{N}\right)\right]\right\}^{2}}<0 .
$$

\section{Appendix D. Proof of Proposition 3}

Using (41), (C.5), (C.6), and the expression for $Q_{S}\left(c_{N}, c_{S}\right)$ in $(42)$ gives the new $\operatorname{LABS}(l, \mu)$ :

$$
\begin{aligned}
& \frac{\mu s_{N}\left\{A_{l} \lambda[\rho-n+2(l+\mu)]+A_{\mu}(\rho-n+\imath \lambda)\right\}}{\eta_{S}(\lambda-1)(l+\mu)} \\
& \quad+\frac{(1-\alpha) s_{N} \lambda\left\{A_{l}[\rho-n+2(l+\mu)]+A_{\mu}(\rho-n+l)\right\} K\left(l, \mu, \tau_{N}, \tau_{S}\right)}{\alpha \eta_{S}(\lambda-1)}=1 \quad \operatorname{LABS}(l, \mu)
\end{aligned}
$$

with $\quad K\left(l, \mu, \tau_{N}, \tau_{S}\right) \equiv \frac{l\left[1+((1-\alpha) / \alpha)\left(1+\tau_{S}\right)\right]\left(1+\tau_{N}\right)+(\mu / \alpha)\left[1+\tau_{N}(1-\alpha)\right]\left(1+\tau_{S}\right)}{l\left[1+((1-\alpha) / \alpha)\left(1+\tau_{N}\right)\left(1+\tau_{S}\right)\right]+(\mu / \alpha)\left[1+\tau_{N}(1-\alpha)\right]\left(1+\tau_{S}\right)} \equiv \frac{\text { num }}{\text { den }}$,

where the baseline model's (33) is obtained for $\alpha=1$ again. We consider the slope of the $\operatorname{LABS}(l, \mu)$ curve in the neighborhood of $\tau_{N}=\tau_{S}=0$, which implies $K()=$.1 . It then follows that the LHS of (D.1) is unambiguously increasing in $\mu$, whereas it is unambiguously increasing in $\imath$ if, and only if,

$$
\frac{\mu\left[A_{\mu}(\lambda \mu-\rho+n)-\lambda A_{l}(\rho-n)\right]}{(l+\mu)^{2}}+\frac{(1-\alpha) \lambda\left(2 A_{l}+A_{\mu}\right)}{\alpha}>0 .
$$

Observe that the first term of (D.2) is positive if, and only if, condition (34) holds, hence (D.2) is actually a weaker condition than (34). Thus, provided (34) holds, the $\operatorname{LABS}(l, \mu)$ curve is again strictly downward sloping and the uniqueness of the steady-state equilibrium is established. Existence of this equilibrium is ensured by the facts that, as in Fig. 3, the LABS curve (D.1) does not intersect the vertical axis even for $l \rightarrow \infty$ because (D.2) ensures $\mu>0$, and the LABN curve (32) is concave and solved by a $l>0$ for $\mu \rightarrow 0$.

Differentiating the K-function with respect to the tariff rates under $\tau_{N}>0$ and $\tau_{S}>0$ yields

$$
\begin{aligned}
\frac{\partial K(\cdot)}{\partial \tau_{N}} & =\frac{l \mu\left(1+\tau_{S}\right)+l^{2}\left[1+\tau_{S}(1-\alpha)\right]}{\alpha(\text { den })^{2}}>0, \\
\frac{\partial K(\cdot)}{\partial \tau_{S}} & =-\frac{l \tau_{N}\left[\mu+((1-\alpha) / \alpha)(l+\mu)\left(1+\tau_{N}\right)\right]}{\operatorname{den}^{2}}<0 .
\end{aligned}
$$

We now discuss the implications for shifts in the LABN and LABS curves. A decrease in $\tau_{N}$ unambiguously reduces the LHS of (D.1), hence $\mu$ must increase to restore Southern labor market equilibrium for any given $l$. Thus, the $L A B S(l, \mu)$ curve shifts to the right, whereas the $\operatorname{LABN}(l, \mu)$ curve still given by $(32)$ is unaffected. This results in a joint increase in both $l$ and $\mu$. A decrease in $\tau_{S}$ has the opposite effects: according to (D.4), the LHS of (D.1) increases, hence $\mu$ must decrease to restore Southern labor market equilibrium for any given $l$. Thus, the $\operatorname{LABS}(l, \mu)$ curve shifts to the left, whereas the $L A B N(l, \mu)$ curve is again unaffected. This results in a joint decrease in both $\iota$ and $\mu$, which completes the proof.

\section{Appendix E. Bilateral trade liberalization}

To capture bilateral trade liberalization, we consider a simultaneous decline in both $\tau_{N}$ and $\tau_{S}$ by the same amount, $d \tau_{N}=d \tau_{S}$. We allow for differences in the levels of tariffs though. Since only the LABS Eq. (D.1) but not the LABN Eq. (32) 
has tariffs in it, we only need to totally differentiate the LHS of (D.1) with respect to $\tau_{N}$ and $\tau_{S}$ and impose $d \tau_{N}=d \tau_{S}=d \tau$, which gives

$$
-\frac{d \tau \imath s_{N}((1-\alpha) / \alpha) \lambda\left\{A_{l}[\rho-n+2(l+\mu)]+A_{\mu}(\rho-n+l)\right\} K_{17}}{\eta_{S}(\lambda-1)\left\{(l+\mu)\left[1+((1-\alpha) / \alpha)\left(1+\tau_{N}\right)\right]+\left[\mu+((1-\alpha) / \alpha)(l+\mu)\left(1+\tau_{N}\right)\right] \tau_{S}\right\}^{2}},
$$

where $K_{17} \equiv \imath\left[-1+((1-\alpha) / \alpha)\left(-1+\tau_{N}+\tau_{N}^{2}-\tau_{S}\right)\right]+\mu\left[-1+\tau_{N}+((1-\alpha) / \alpha)\left(-1+\tau_{N}+\tau_{N}^{2}-\tau_{S}\right)-\tau_{S}\right]$. A sufficient condition for $K_{17}<0$ is $-1+((1-\alpha) / \alpha)\left(-1+\tau_{N}+\tau_{N}^{2}-\tau_{S}\right)<0$, for which $\tau_{N}\left(1+\tau_{N}\right)<1+\tau_{S}$ is sufficient, for which in turn $\tau_{N}$ $\left(1+\tau_{N}\right)<1$ is sufficient. This latter condition is fulfilled for any $\tau_{N} \in(0,0.618034)$. Hence for this reasonable range, a fall in $\tau_{N}$ and $\tau_{S}$ by the same size reduces the LHS of (D.1). To restore equilibrium, there must be an increase in $\mu$ and thus a rightward shift of the LABS curve as in Fig. 4. Consequently, the levels of both $\mu$ and $\imath$ increase, which proves the qualitative equivalence of bilateral trade liberalization with unilateral Northern trade liberalization as is claimed in part ii of our Main Result 2.

\section{References}

Baldwin, R.E., Forslid, R., 1999. Incremental trade policy and endogenous growth: a q-theory approach. Journal of Economic Dynamics and Control 23 (5-6), 797-822.

Ben-David, D., Loewy, M.B., 2000. Knowledge dissemination, capital accumulation, trade, and endogenous growth. Oxford Economic Papers 52 (4), 637-650.

Berrier, E.F., 1996. Global patent cost must be reduced. IDEA The Journal of Law and Technology 36, 473-511.

Christiaans, T., 2004. Types of balanced growth. Economics Letters 82 (2), 253-258.

Dalgaard, C.-J., Kreiner, C.T., 2001. Is declining productivity inevitable? Journal of Economic Growth 6 (3), 187-203.

Dinopoulos, E., Segerstrom, P.S., 1999a. A Schumpeterian model of protection and relative wages. American Economic Review 89 (3), $450-472$.

Dinopoulos, E., Segerstrom, P.S., 1999b. The dynamic effects of contingent tariffs. Journal of International Economics 47 (1), $191-222$.

Dinopoulos, E., Segerstrom, P.S., 2007. North-South Trade and Economic Growth. Manuscript, University of Florida and Stockholm School of Economics.

Dinopoulos, E., Segerstrom, P.S., 2009. Intellectual property rights, multinational firms and economic growth. Journal of Development Economics, in press, doi:10.1016/j.jdeveco.2009.01.007.

Dinopoulos, E., Syropoulos, C., 1997. Tariffs and Schumpeterian growth. Journal of International Economics 42 (3-4), 425-452.

Dinopoulos, E., Syropoulos, C., 2007. Rent protection as a barrier to innovation and growth. Economic Theory 32 (2), 309-332.

Dinopoulos, E., Thompson, P., 1999. Scale effects in Schumpeterian models of economic growth. Journal of Evolutionary Economics 9 (2), 157-185.

Grieben, W.-H., 2004. Schumpeterian growth, north-south trade and wage rigidity. Contributions to Macroeconomics 4 (1) Article 9.

Grieben, W.-H., 2005. A Schumpeterian north-south growth model of trade and wage inequality. Review of International Economics 13 (1), $106-128$.

Grieben, W.-H., 2009. Can countries with severe labor market frictions gain from globalization? Review of Development Economics 13 (2), $230-247$.

Grossman, G., Helpman, E., 1991. Endogenous product cycles. Economic Journal 101 (408), 1214-1229.

Gustafsson, P.S., Segerstrom, P.S., 2008. North-south trade with multinational firms and increasing product variety. Manuscript, NIER Stockholm and Stockholm School of Economics.

Ha, J., Howitt, P., 2007. Accounting for trends in productivity and R\&D: a Schumpeterian critique of semi-endogenous growth theory. Journal of Money, Credit, and Banking 39 (4), 733-774.

Hallak, J.C., Levinsohn, J., 2008. Fooling ourselves: evaluating the globalization and growth debate. In: Zedillo, E. (Ed.), The Future of Globalization: Explorations in Light of Recent Turbulence. Routledge, pp. 209-223.

Howitt, P., 1999. Steady endogenous growth with population and R\&D inputs growing. Journal of Political Economy 107 (4), 715-730.

Jones, C.I., 1995a. Time series tests of endogenous growth models. Quarterly Journal of Economics 110 (2), $495-525$.

Jones, C.I., 1995b. R\&D-based models of economic growth. Journal of Political Economy 103 (4), 759-784.

Jones, C.I., 1999. Growth: with or without scale effects? American Economic Review 89 (2), 139-144.

Jones, C.I., 2005. Growth and ideas. In: Aghion, P., Durlauf, S. (Eds.), Handbook of Economic Growth, vol. 1B. North-Holland, Amsterdam, pp. $1063-1111$.

Laincz, C.A., Peretto, P.F., 2006. Scale effects in endogenous growth theory: an error of aggregation not specification. Journal of Economic Growth 11 (3), $263-288$.

Lewer, J.J., Van den Berg, H., 2003. How large is international trade's effect on economic growth? Journal of Economic Surveys 17 (3), $363-396$.

Lanjouw, J.O., Cockburn, I., 2000. Do patents matter? Empirical evidence after GATT. NBER Working Paper no. 7495.

Lu, C.-H., 2007. Moving up or moving out? A unified theory of R\&D, FDI, and trade. Journal of International Economics 71 (2), $324-343$.

Lucas Jr., R.E., 2009. Trade and the diffusion of the industrial revolution. American Economic Journal: Macroeconomics 1 (1), 1-25.

Madsen, J.B., 2007. Are there diminishing returns to R\&D? Economics Letters 95 (2), 161-166.

Madsen, J.B., 2008. Semi-endogenous versus Schumpeterian growth models: testing the knowledge production function using international data. Journal of Economic Growth 13 (1), 1-26.

Neary, J.P, 2004. Europe on the road to Doha: towards a new global trade round? CESifo Economic Studies 50 (2), $319-332$.

Noguer, M., Siscart, M., 2005. Trade raises income: a precise and robust result. Journal of International Economics 65 (2), $447-460$.

Peretto, P.F., 1998. Technological change and population growth. Journal of Economic Growth 3 (4), 283-311.

Peretto, P.F., Smulders, S., 2002. Technological distance, growth and scale effects. Economic Journal 112 (481), 603-624.

Rivera-Batiz, L.A., Romer, P.M., 1991. Economic integration and endogenous growth. Quarterly Journal of Economics 106 (2), 531-555.

Rodríguez, F., Rodrik, D., 2000. Trade policy and economic growth: a skeptics guide to the cross-national evidence. In: Bernanke, B., Rogoff, K. (Eds.), NBER Macroeconomics Annual, vol. 15. MIT Press, Cambridge, pp. 261-325.

Scotchmer, S., 2004. Innovation and Incentives. MIT Press, Cambridge, MA.

Segerstrom, P.S., 1998. Endogenous growth without scale effects. American Economic Review 88 (5), 1290-1310.

Segerstrom, P.S., 2000. The long-run growth effects of R\&D subsidies. Journal of Economic Growth 5 (3), 277-305.

Șener, F., 2001. Schumpeterian unemployment, trade and wages. Journal of International Economics 54 (1), $119-148$.

Sener, F., 2006. Intellectual property rights and rent protection in a north-south product-cycle model. Manuscript. Union College, Schenectady.

Şener, F., 2008. R\&D policies, endogenous growth and scale effects. Journal of Economic Dynamics and Control 32 (12), $3895-3916$.

Şener, F., Zhao, L., 2009. Globalization, R\&D and the iPod cycle. Journal of International Economics 77 (1), $101-108$.

Strulik, H., 2005. The role of human capital and population growth in R\&D-based models of economic growth. Review of International Economics 13 (1), 129-145.

Temple, J., 2003. The long-run implications of growth theories. Journal of Economic Surveys 17 (3), 497-510.

Van den Berg, H., 2004. International Economics. McGraw-Hill/Irwin, New York.

Wacziarg, R., Welch, K.H., 2008. Trade liberalization and growth: new evidence. World Bank Economic Review 22 (2), $187-231$. 
Wälde, K., Wood, C., 2004. The empirics of trade and growth: where are the policy recommendations? International Economics and Economic Policy 1 (2-3), $275-292$.

Winters, L.A., 2004. Trade liberalization and economic performance: an overview. Economic Journal 114 (493), F4-F21.

Wood, A., 1995. How trade hurt unskilled workers. Journal of Economic Perspectives 9 (3), 57-80.

World Bank, 2005. World Development Indicators, Washington, DC.

Young, A., 1998. Growth without scale effects. Journal of Political Economy 106 (1), 41-63. 